\title{
Trim9 Deletion Alters the Morphogenesis of Developing and Adult-Born Hippocampal Neurons and Impairs Spatial Learning and Memory
}

\author{
Cortney C. Winkle, ${ }^{1 *}$ Reid H. J. Olsen, ${ }^{2 *}$ Hyojin Kim, ${ }^{1}$ Sheryl S. Moy, ${ }^{3,4}$ Juan Song, ${ }^{2,5}$ and Stephanie L. Gupton ${ }^{5,6,7}$ \\ ${ }^{1}$ Curriculum in Neurobiology, ${ }^{2}$ Department of Pharmacology, ${ }^{3}$ Department of Psychiatry, ${ }^{4}$ Carolina Institute for Developmental Disabilities, ${ }^{5}$ University of \\ North Carolina Neuroscience Center, ${ }^{6}$ Department of Cell Biology and Physiology, and ${ }^{2}$ Lineberger Comprehensive Cancer Center, University of North \\ Carolina, Chapel Hill, North Carolina 27599
}

During hippocampal development, newly born neurons migrate to appropriate destinations, extend axons, and ramify dendritic arbors to establish functional circuitry. These developmental stages are recapitulated in the dentate gyrus of the adult hippocampus, where neurons are continuously generated and subsequently incorporate into existing, local circuitry. Here we demonstrate that the E3 ubiquitin ligase TRIM9 regulates these developmental stages in embryonic and adult-born mouse hippocampal neurons in vitro and in vivo. Embryonic hippocampal and adult-born dentate granule neurons lacking Trim 9 exhibit several morphological defects, including excessive dendritic arborization. Although gross anatomy of the hippocampus was not detectably altered by Trim 9 deletion, a significant number of Trim $9^{-1-}$ adult-born dentate neurons localized inappropriately. These morphological and localization defects of hippocampal neurons in Trim $9^{-1-}$ mice were associated with extreme deficits in spatial learning and memory, suggesting that TRIM9-directed neuronal morphogenesis may be involved in hippocampal-dependent behaviors.

Key words: arborization; learning; memory; neurogenesis; TRIM9

\section{Significance Statement}

Appropriate generation and incorporation of adult-born neurons in the dentate gyrus are critical for spatial learning and memory and other hippocampal functions. Here we identify the brain-enriched E3 ubiquitin ligase TRIM9 as a novel regulator of embryonic and adult hippocampal neuron shape acquisition and hippocampal-dependent behaviors. Genetic deletion of Trim 9 elevated dendritic arborization of hippocampal neurons in vitro and in vivo. Adult-born dentate granule cells lacking Trim9 similarly exhibited excessive dendritic arborization and mislocalization of cell bodies in vivo. These cellular defects were associated with severe deficits in spatial learning and memory.

\section{Introduction}

The hippocampus is a subcortical structure associated with learning and memory. Developing hippocampal neurons progress

Received Oct. 26, 2015; revised Feb. 17, 2016; accepted March 7, 2016.

Author contributions: C.C.W., R.H.J.O., S.S.M., J.S., and S.L.G. designed research; C.C.W., R.H.J.O., H.K., S.S.M., and S.L.G. performed research; C.C.W., R.H.J.O., H.K., and S.S.M. analyzed data; C.C.W., R.H.J.O., H.K., S.S.M., J.S., and S.L.G. wrote the paper.

This work was supported by the National Institutes of Health Grants R01-GM108970 to S.L.G., F31-NS087837 to C.C.W., F31-NS093917 to R.H.J.0., U54-HD079124 to S.S.M., and MH106939 to J.S., Brain and Behavioral Foundation to J.S., American Heart Association to J.S., Whitehall Foundation to J.S., the University of North Carolina Department of Pharmacology startup Fund to J.S., and Lineberger Comprehensive Cancer Center startup Funds to S.L.G. We thank Viktoriya Nikolova and Natallia Riddick (Mouse Behavioral Phenotyping Core of the Carolina Institute for Developmental Disabilities); Juli Valtschanoff for help with DAB staining; and Carey Hanlin for assistance with the mouse colony.

The authors declare no competing financial interests.

${ }^{*}$ C.C.W. and R.H.J.O. contributed equally to this study.

Correspondence should be addressed to either Dr. Stephanie L. Gupton or Dr. Juan Song, University of North Carolina Neuroscience Center, Chapel Hill, NC 27599. E-mail: sgupton@email.unc.edu or juansong@email.unc.edu. through stereotypical stages of morphogenesis (Dotti et al., 1988; Bradke and Dotti, 2000). Neuronal processes ramify to innervate multiple synaptic partners, and synapses change size and shape in response to extracellular signals and neural activity (Song et al., 2015). Appropriate morphogenesis requires regulated cytoskeletal dynamics to provide protrusive force to alter cell shape and delivery of materials for plasma membrane expansion (Pfenninger, 2009; Gupton and Gertler, 2010; Dent et al., 2011; Menon and Gupton, 2016; Winkle and Gupton, 2016).

Hippocampal adult-born neurons recapitulate stages of embryonic neuronal development in a mature nervous system and participate in specific functions, including learning, memory, stress responses, and mood regulation (Deng et al., 2010; Ming and Song, 2011). These neurons are generated in the subgranular 
zone (SGZ) of the dentate gyrus (DG), migrate locally within the granule cell layer (GCL), mature into granule neurons, and integrate into existing circuitry. Aberrant adult neurogenesis is linked to neurological disorders (Deng et al., 2010; Christian et al., 2014). For instance, deletion of Pten or DISC1 knockdown is associated with aberrant adult-born granule cell morphology linked to epilepsy or behavioral deficits (Deng et al., 2009; Pun et al., 2012; Zhou et al., 2013). Although aberrant development of adult-born neurons may disrupt behavior and elicit pathology, the molecular factors that regulate development, morphogenesis, and integration of adult-born hippocampal neurons are largely unknown.

TRIM9 is an evolutionarily conserved member of the TRIpartite Motif (TRIM) family of ubiquitin ligases (Berti et al., 2002; Tanji et al., 2010). We recently identified TRIM9 as a regulator of neuronal morphogenesis in cortical neurons (Winkle et al., 2014; Menon et al., 2015). TRIM9 directly interacts with exocytic t-SNARE SNAP25 (Li et al., 2001), the actin polymerase VASP (Menon et al., 2015), and DCC, a receptor for the axon guidance cue netrin (Winkle et al., 2014). Deletion of Trim9 in cortical neurons is associated with elevated exocytosis, increased stability of growth cone filopodia, and loss of netrin responsiveness in vitro. These phenotypes are associated with aberrant branching and projection of cortical axons both in vitro and in vivo (Winkle et al., 2014; Menon et al., 2015), suggesting that TRIM9 regulates membrane delivery and cytoskeletal dynamics powering cortical neuron morphogenesis.

The role for TRIM9 in neuronal morphogenesis is evolutionarily conserved and may extend toward the organization of synapses. In invertebrates, Trim 9 orthologs are implicated in netrin-dependent cell migration, axon guidance, and branching (Hao et al., 2010; Morikawa et al., 2011; Morf et al., 2013). In Drosophila, neural activity regulates TRIM9 expression to establish sensory afferent topographic maps (Yang et al., 2014). TRIM9 localizes to the somal compartment and proximal dendrites of hippocampal neurons (Tanji et al., 2010) and is a component of the postsynaptic density (Jordan et al., 2004), yet little is known regarding the role of TRIM9 in dendrites. Netrin-1 and DCC are present in the developing and adult hippocampus, and mice deficient in either genes exhibit neuroanatomical defects (Serafini et al., 1996; Fazeli et al., 1997; Bin et al., 2015; Yung et al., 2015) and altered spontaneous neural activity (Barallobre et al., 2000). TRIM9 mRNA is also enriched in maturing adult-born neurons (Chatzi et al., 2016). Thus, TRIM9 is poised to function in netrin-dependent hippocampal development and adult neurogenesis.

Here we identify a role for TRIM9 in the control of hippocampal neuron morphogenesis in the developing and adult hippocampus. Deletion of murine Trim 9 caused exuberant arborization and/or protrusion of dendrites and axons in embryonic and adult-born hippocampal neurons, mislocalization of adult-born neurons in vivo, and decreased dendritic spine density. These defects were associated with severely impaired hippocampal-dependent memory. Our study supports a role for TRIM9-mediated morphogenesis in higher neural processes, which is bolstered by the evolutionarily conserved function of TRIM9 in neuronal morphogenesis, and a recent genome-wide association study that identified top-ranked SNPs within the human TRIM9 gene in patients with schizoaffective disorder (Kanazawa et al., 2013).

\section{Materials and Methods}

Animals. All mouse lines were on a C57BL/6J background and bred at the University of North Carolina with approval from the Institutional Ani- mal Care and Use Committee. Timed pregnant females were obtained by placing male and female mice together overnight; the following day was designated as E0.5 if the female had a vaginal plug. Trim $9^{-1-}$, Trim $9^{f l / f l}$, and Thyl-GFP mice were described (Feng et al., 2000; Winkle et al., 2014). A Nex-Cre line (from Dr. Klaus Nave) (Goebbels et al., 2006) and

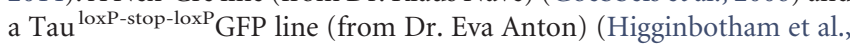
2012) were crossed with Trim $9^{f l / f l}$ mice.

Antibodies, reagents, and plasmids. Antibodies include the following: NH2-terminal TRIM9 rabbit polyclonal (generated using murine TRIM9 recombinant protein amino acids $158-271)$, $\mathrm{COOH}$-terminal TRIM9 rabbit polyclonal raised against $\mathrm{COOH}$ of human TRIM9 (Tanji et al., 2010), mouse monoclonal against human $\beta$ III-tubulin (TujI SCBT, 1:2000), mouse anti-Myc (SCBT, 1:1000), anti-GFP chicken (Aves, ab1020, 1:2000), rabbit anti GFAP (Invitrogen, 1:3000), goat anti-GFP (Rockland, 1:250), goat anti-doublecortin (DCX) (SCBT, 1:500), mouse anti-nestin (EMD Millipore, 1:250), rat anti-mCherry (ab167453), and rabbit anti-prox1 (Abcam, 1:500). Fluorescent secondary antibodies and fluorescent phalloidin labeled with AlexaFluor-488, AlexaFluor-568, or AlexaFluor-647 were from Invitrogen. DAPI was from Thermo-Fisher (Molecular Probes). Netrin-1 was concentrated from conditioned media from netrin-1-expressing HEK293 cells (Serafini et al., 1994; Lebrand et al., 2004). AAV viruses for expressing mCherry or GFP under control of the CaMKIIpromoter (AAV2-CaMKII-eGFP and AAV2-CaMKIImCherry) were obtained through the UNC vector core at a titer of $10^{12}$. GFP-expressing retroviruses were a generous gift from the laboratory of Dr. Hongjun Song and have been previously described (Song et al., 2013). Fluorescent and epitope-tagged TRIM9 mammalian expression plasmids were previously described (Winkle et al., 2014). The pHluorinDCC plasmid is similar to the mCherry-DCC plasmid described by Winkle et al. (2014), except that the fluorophore has been switched.

Immunoblotting, coimmunoprecipitation. SDS-PAGE and immunoblot analysis were performed using standard procedures with far-redconjugated $2^{\circ}$ antibodies (LiCor). Signal was detected with Odyssey Imager (LiCor). The coimmunoprecipitation in Figure 1 was performed using IgG-conjugated A/G beads (SCBT) to preclear lysates for $1.5 \mathrm{~h}$ at $4^{\circ} \mathrm{C}$ with agitation. NH2-terminal TRIM9 antibody was incubated with precleared lysates for $2 \mathrm{~h}$ before the addition of agarose protein A/G beads (SCBT) overnight at $4^{\circ} \mathrm{C}$ to precipitate target proteins. For TRIM9 and DCC coimmunoprecipitations, lysates were precleared with a fluorescent chicken anti-goat 594 or protein A/G beads (SCBT). NH2TRIM9 antibody was incubated with precleared lysates for $2 \mathrm{~h}$ before the addition of agarose protein $\mathrm{A} / \mathrm{G}$ beads (SCBT) overnight at $4^{\circ} \mathrm{C}$ to precipitate target proteins. In a separate reaction, goat polyclonal DCC antibody conjugated to A/G (SCBT, A-20) beads were incubated in lysates overnight at $4^{\circ} \mathrm{C}$ to precipitate target proteins. Beads were washed three times with lysis buffer, and bound proteins were prepared in sample buffer, resolved by SDS-PAGE, and analyzed by immunoblotting. Immunoblots were probed with COOH-terminal TRIM9 (see Fig. 1) (Tanji et al., 2010), or NH2 TRIM9 (see Fig. 2), goat polyclonal DCC (SCBT) and mouse monoclonal GAPDH (SCBT) as a loading control.

Embryonic hippocampal neuron culture, transfection, and imaging. E15.5 dissociated hippocampal neuron cultures were prepared as described previously (Viesselmann et al., 2011). Briefly, hippocampi were microdissected, and neurons were dissociated with trypsin and plated on poly-D-lysine (Sigma)-coated coverglass, glass-bottom movie dishes (Matek) or tissue culture plastic in Neurobasal media (Invitrogen) supplemented with B27 (Invitrogen). For transfection of Myc-tagged TRIM9 variants, or cotransfection of mCherry-TRIM9 and DCCpHluorin, neurons were resuspended after dissociation in Lonza Nucleofector solution (VPG-1001) and electroporated according to the manufacturer's protocol. To assay the effects of netrin-1 stimulation, 250 $\mathrm{ng} / \mathrm{ml}$ netrin-1 was bath-applied for $24 \mathrm{~h}$ followed by fixation and immunofluorescence. Control and netrin-1-treated cells were fixed in $4 \%$ PFA at the indicated time points, permeabilized for $10 \mathrm{~min}$ in $0.1 \%$ Triton X-100, blocked for $30 \mathrm{~min}$ in $10 \% \mathrm{BSA}$, and stained with indicated primary antibodies for $1 \mathrm{~h}$ at room temperature. Following three washes, species-appropriate, spectrally distinct fluorescent secondary antibodies were added and allowed to incubate for $1 \mathrm{~h}$ at room temperature. Following three washes, cells were mounted in a TRIS/glycerol/ $n$-propyl- 
gallate-based mounting media for imaging. Wide-field epifluorescence images of neurons were analyzed.

Live cell imaging. Time-lapse total internal reflection fluorescence images of Trim $9^{+/+}$hippocampal neurons expressing mCherry-TRIM9 and DCC-pHluorin at 2 DIV were acquired with an Olympus IX81ZDC2 inverted microscope with MetaMorph acquisition software, an Andor iXon EM-CCD, and a Tokai Hit environmental chamber, which maintained $37^{\circ} \mathrm{C}$ and $5 \% \mathrm{CO}_{2}$. Pearson's correlation of colocalization between mcherry-TRIM9 and DCC-pHlurin was performed using whole-cell ROIs and an Intensity Correlation Analysis (Coloc2) plugin for ImageJ (Schindelin et al., 2012). Scrambled images were used as correlative controls.

In vivo. All Thy1-GFP and Tau NEX-Cre mice used for neuroanatomical studies were anesthetized with an intraperitoneal injection of $1.2 \%$ avertin and intracardially perfused with $4 \%$ PFA. Brains were removed and fixed in $4 \%$ PFA for a subsequent $48 \mathrm{~h}$, rinsed with $1 \times \mathrm{PBS}$, and rested in $70 \% \mathrm{EtOH}$ for at least $24 \mathrm{~h}$ before vibratome sectioning. For projection analysis in NexCre/Tau ${ }^{\text {loxP-stop-loxP }}$ GFP littermates, $100 \mu \mathrm{m}$ coronal sections were cut, and every other section was permeabilized in detergent solution $(1 \times \mathrm{PBS}+0.1 \%$ Triton X-100 $+0.2 \%$ Tween 20 ) for $1 \mathrm{~h}$ on a shaker at room temperatures. Sections were blocked in $10 \%$ BSA in $1 \times$ PBS for $5 \mathrm{~h}$, then placed in primary antibody solution (anti-GFP chicken [Aves, ab1020] 1:2000, anti-GFAP rabbit [Abcam, ab7260] 1:2500 in 1\% BSA in PBS) for $24 \mathrm{~h}$ on a shaker at $4^{\circ} \mathrm{C}$. Primary antibodies were removed and sections were rinsed in $1 \times \mathrm{PBS}$ for $1 \mathrm{~h}$ before the addition of secondary antibody solution (AlexaFluor-488 chicken, AlexaFluor-561 or AlexaFluor-647 rabbit $+1 \%$ BSA in $1 \times$ PBS) for $24 \mathrm{~h}$ on a covered shaker at $4^{\circ} \mathrm{C}$. After postsecondary rinsing with $1 \times \mathrm{PBS}$, sections were mounted in DPX mountant (VWR) and were imaged with the $10 \times$ objective on the LSCM described below. Brains from Thyl-GFP littermates were similarly prepared and imaged with the $20 \times$ objective on the LSCM described below. Maximal projections of multiarea $Z$ stacks of serial coronal sections containing the hippocampus of 5-week-old NEX-Cre/

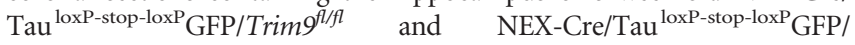
Trim $9^{+/+}$littermates were collected.

For in vivo viral injections, 6-week-old Trim $9^{+/+}$and Trim $9^{-/-}$were stereotaxically injected with a GFP-expressing retrovirus driven by the ubiquitin promoter $(300 \mathrm{nl}$ at $100 \mathrm{nl} / \mathrm{min}$, using a pump-driven $5 \mu \mathrm{l}$ Hamilton syringe and a 33 gauge needle). Stereotaxic coordinates targeted the DG (anteroposterior -2.0 , mediolateral \pm-1.5 , dorsoventral -2.3 ). At 14 and $28 \mathrm{~d}$ post injection (DPI), mice were deeply anesthetized with a ketamine/xylazine mixture and transcardially perfused with $10 \mathrm{ml}$ PBS, pH 7.4, followed by $10 \mathrm{ml} 4 \%$ PFA pH 7.4. Brains were removed and fixed overnight at $4^{\circ} \mathrm{C}$ in $4 \%$ PFA, followed by cryoprotection with $30 \%$ sucrose for $48 \mathrm{~h}$. Brains were sectioned coronally using a Leica sliding microtome at $40 \mu \mathrm{m}$ and stored in ethylene-glycol/sucrose/PBS containing antifreeze solution until immunohistochemical processing. For in vivo labeling of mature neurons in CA1 and the DG of the adult hippocampus, a similar injection paradigm was followed, substituting AAV2-CaMKII-mCherry (CA1: anteroposterior -2.0 , mediolateral \pm -1.5 , dorsoventral -1.25 ) and AAV2-CaMKII-eGFP (DG granule-cell layer: anteroposterior -2.0 , mediolateral \pm-1.5 , DV -2.0$)$. After 2 weeks, mice were transcardially perfused and brains processed as described above.

Immunohistochemistry. For DAB staining, floating sections were subjected to heat-induced antigen retrieval in $10 \mathrm{~mm}$ sodium citrate, $\mathrm{pH}$ 6.0, for $10 \mathrm{~min}$ followed by blocking for an hour in 1\% BSA and overnight incubation in $5 \mu \mathrm{g} / \mathrm{ml}$ antibody solution in $1 \%$ BSA with $0.3 \%$ Triton $\mathrm{X}-100$ in PBS. After $3 \times 10$ min rinses in PBS, sections were treated with $\mathrm{DAB}$ chromogen solution for $20 \mathrm{~min}$ and rinsed with deionized water $3 \times$ before mounting. For immunofluorescence, for all experiments except for detection of TRIM9 by immunohistochemistry in GFP-labeled adult-born neurons, floating sections were permeabilized in PBS containing $0.5 \%$ Triton X-100 (PBST) for $1 \mathrm{~h}$. For TRIM9 fluorescence immunohistochemistry, slide-mounted tissues were permeabilized by incubation in $100 \%$ methanol at $-20^{\circ} \mathrm{C}$ for $30 \mathrm{~min}$, followed by three 10 min washes in PBS. With the exception of the removal of Triton X-100 for TRIM9 immunofluorescence staining, tissues were then blocked in $5 \%$ donkey serum in PBST (PBST-DS) for an additional hour. Subsequently, tissue sections were incubated with primary antibody overnight at room temperature before $3 \times 10$ min washes in PBST and incubation in Alexa-conjugated secondary antibody for $2 \mathrm{~h}$ at room temperature in PBST-DS. Sections were again washed $3 \times$ in PBST followed by 3 washes in PBS. Nuclei were counterstained with DAPI at a concentration of 1.2 $\mu \mathrm{M}$ in the penultimate wash. Tissues were subsequently mounted on charged slides before confocal imaging.

Microscope descriptions. Immunocytochemistry images were collected on an Olympus IX81-ZDC2 inverted microscope with the following objective lenses: a UPLFLN 40×/1.39 NA objective (Olympus, 1, 2, and 3 DIV), UPlanSapo $20 \times$ oil/0.85 NA objective (Olympus, 5 DIV), an automated XYZ stage (Prior), and an Andor iXon EM-CCD. Images were acquired by MetaMorph software. Confocal imaging of brain sections was performed using a Fluoview FV1000 microscope (Olympus) equipped with 405, 488, 568, and $633 \mathrm{~nm}$ lasers. Acquisition of neuroanatomical images at 3 and 5 weeks postnatal were captured with a $20 \times 1$ 0.75 NA PlanApochromat objective lens and 10×/0.4 NA Plan Apochromat objective lens, respectively. Acquisition of retrovirally labeled neurons 14 DPI was performed using a tiling method via $10 \times$ objective (NA 04) to capture the entire DG for both somatic location and axonal targeting. Dendrites of neurons 14 DPI were captured using a $40 \times$ oil 1.3 NA with a $1 \mu \mathrm{m}$ step size. Synapses of retrovirally labeled neurons 28 DPI were captured with a $60 \times$ oil objective at $2 \times$ zoom and $0.33 \mu \mathrm{m}$ step size. Images of DCX and nestin-stained retrovirally naive tissue were acquired with a $40 \times 1.3 \mathrm{NA} 1.42$ objective. Axons from $\mathrm{GFP}^{+}$adultborn granule cells 28 DPI were imaged in CA3 using an Olympus confocal microscope with a $60 \times$ oil objective.

Image analysis. In vitro cell images at 1 and 2 DIV were analyzed as follows: Stage 1 was defined by a lack of $\beta$ III-tubulin and F-actin-positive neurites extending from the soma. Stage 2 is defined by the presence of $\beta$ III-tubulin and F-actin-positive neurites extending from the soma. Stage 3 neurons are defined similarly but also have a single neurite that is at least 2 times the length of other neurites, presumed to be the axon (Dotti et al., 1988). For in vitro images at 3 and 5 DIV, all neurites were measured for length and identified as primary (extending from the soma), secondary (extending from the primary neurites), or tertiary (extending from secondary). The longest neurite extending from the soma was defined as the axon ( $n=3$ separate experiments, at least 50 cells per condition).

Position-matched sections between littermates were analyzed for axon projection comparisons and dendritic complexity. For Thyl-GFP littermates, the number of $\mathrm{GFP}^{+}$soma were counted and divided by the number of total nuclei in a given ROI. To compare $\mathrm{GFP}^{+}$dendritic arbors, the $Z$-stacks of littermates were processed into maximum projection images, a threshold was applied to the area of $\mathrm{GFP}^{+}$fibers. The resulting area was then divided by the number of $\mathrm{GFP}^{+}$soma within the ROI. To measure axonal material, ROIs were drawn in ImageJ around the area containing $\mathrm{GFP}^{+}$fibers in maximum projection images of position-matched coronal sections of NEX-Cre/Tau ${ }^{\text {loxP-stop-loxP }}$ GFP littermates.

To quantify somal localization in vivo, the GCL of a whole DG (average of 6/animal, $n=3$ per group) was horizontally divided into three equalsized compartments (see Fig. 5B), and the number of soma residing in these three layers (inner layer, middle layer, outer layer) as well as the hilar region were quantified. Data were analyzed using ANOVA with post hoc $t$ tests using a Bonferroni correction.

Dendrites of $\mathrm{GFP}^{+}$neurons 14 DPI were analyzed using the simpleneurite tracer plugin for ImageJ (Schindelin et al., 2012). Neurons (10 per animal, $n=3$ per group) were traced in three dimensions to allow for accurate reconstruction of complexity and path length. The length of the primary (longest) dendrite was measured, as well as the total number of branches, and the order of these branches (secondary, tertiary, etc.). Sholl analysis was performed by counting the number of crossings by dendrites of concentric circles originating at the soma with increasing radii of 10 $\mu \mathrm{m}$. Sholl analysis data were analyzed using a two-way ANOVA with distance from soma and genotype as the independent variables. Additionally, cumulative branching was analyzed using KolmagorovSmirnoff test of best fit. Post hoc multiple comparisons were conducted using the Holm-Sidak correction. Length of longest dendrite, the highest branch order (e.g., primary, secondary, tertiary), total branches, and 
total length were analyzed using a two-tailed $t$ test. In all tests, data were analyzed for equality of variances. Initial dendrite cross-sectional areas and lengths were analyzed using the surface renderer and object analyzer advanced tools in Huygens software (version 14.10, Scientific Volume Imaging). The dendrite arising from the soma and extending to the first branch point was selected, and its volume and length were quantified using Huygens software. The average cross-sectional area was calculated by volume divided by length of the initial dendrite segments.

Analysis of spine density and classification of the subtype spines was performed on 3D image stacks using NeuronStudio $(n=3$ animals per group, $>1800$ spines per animal). NeuronStudio supports automated labeling and classifying of spines (mushroom, stubby, and thin) using the threshold-based segmentation (Rodriguez et al., 2008). Threedimensional image stacks were loaded, auto-aligned, and smoothed using a Gaussian filter. Spine density was quantified by dividing the number of spines by dendrite length. Spines from secondary and tertiary branches were scored, and analyses were performed by an experimenter blind to genotype and the experimental manipulation.

$\mathrm{GFP}^{+}$axonal segments adult-born granule cells at 28 DPI were semimanually traced in 3D using the simple-neurite tracer plugin for FIJI (Schindelin et al., 2012). The density of protrusions per $100 \mu \mathrm{m}$ for any individual animal was not normally distributed, negating comparing the average per animal. Instead, the pooled data are shown per animal in Figure $9 D$, and were compared by Mann-Whitney test. Gross hippocampal morphology following viral labeling of mature CaMKII-expressing pyramidal cells in CA1 and granule cells in the CA1 and the DG was assessed qualitatively by microscopy, examined for displacement of CA1 pyramidal cells or DG granule cells, as well as the targeting location of axons from the mature DG granule cells. Thickness of CA1 pyramidal cell layer was assessed by imaging coronal sections ( $n=3$ per group, 3 or 4 sections per animal) at $40 \times$ on a laser-scanning confocal microscope. The length of a line drawn from the top (dorsal) to the bottom (ventral) of the dense band of nuclei was measured in FIJI and averaged within each animal. Group means were compared via two-tailed $t$ test.

Behavioral phenotyping. Subjects were 13 Trim $9^{+/+}$mice $(8$ males and 5 females) and 20 Trim $9^{-1-}$ mice ( 6 males and 14 females), taken from 8 litters. Testing began when animals were $\sim 5-7$ weeks of age. The testing regimen was conducted across 10 weeks, so that mice were only examined in one or two procedures each week, to allow recovery between each test. The regimen was also designed to have the least aversive assays, such as elevated plus maze and open field, at the beginning of the study, and the more stressful procedures, such as the Morris Water Maze, near the end, to help minimize any carryover effects. This also allows for gradual acclimation of the mice to handling, the laboratory environment, and novel testing chambers, so that mice were familiar with being moved and handled by the time testing began for more complex learning task in the water maze. This phenotyping battery has been standardized and refined across multiple inbred mouse strains and mutant lines (Pfankuch et al., 2005; Moy et al., 2008, 2009a, b; Haley et al., 2013; Olsen et al., 2013a, 2013b; Raber et al., 2014; Vorhees and Williams, 2014; Urban et al., 2015). For each procedure, measures were taken by an observer blind to mouse genotype $\left(\operatorname{Trim} 9^{+/+}\right.$or $\left.\operatorname{Trim} 9^{-/-}\right)$. Behavioral data were analyzed using one-way or repeated measures ANOVA, with factor genotype. Fisher's protected least-significant difference tests were used for comparing group means only when a significant $F$ value was determined. Within-group comparisons were conducted to determine side preference in the three-chamber test for social approach, and for quadrant preference in the Morris Water Maze. For all comparisons, significance was set at $p<0.05$.

Elevated plus maze. Mice were given one $5 \mathrm{~min}$ trial on the plus maze, which had two walled arms (the closed arms, $20 \mathrm{~cm}$ in height) and two open arms. The maze was elevated $50 \mathrm{~cm}$ from the floor, and the arms were $30 \mathrm{~cm}$ long. Animals were placed on the center section $(8 \mathrm{~cm} \times 8$ $\mathrm{cm}$ ) and allowed to freely explore the maze. Measures were taken of time on, and number of entries into, the open and closed arms.

Marble-burying assay. Mice were tested in a Plexiglas cage located in a sound-attenuating chamber with ceiling light and fan. The cage contained $5 \mathrm{~cm}$ of corncob bedding, with 20 black glass marbles $(14 \mathrm{~mm}$ diameter) arranged in an equidistant $5 \times 4$ grid on top of the bedding.
Subjects were given access to the marbles for $30 \mathrm{~min}$. Measures were taken of the number of buried marbles (two-thirds of the marble covered by the bedding).

Buried food test for olfactory function. Several days before the olfactory test, an unfamiliar food (Froot Loops, Kellogg) was placed overnight in the home cages of the mice. Observations of consumption were taken to ensure that the novel food was palatable. At 16-20 h before the test, all food was removed from the home cage. On the day of the test, each mouse was placed in a large, clean tub cage $(46 \mathrm{~cm}$ length $\times 23.5 \mathrm{~cm}$ width $\times 20 \mathrm{~cm}$ height), containing paper chip bedding ( $3 \mathrm{~cm}$ deep), and allowed to explore for $5 \mathrm{~min}$. The animal was removed from the cage, and one Froot Loop was buried in the cage bedding. The animal was then returned to the cage and given $15 \mathrm{~min}$ to locate the buried food. Measures were taken of latency to find the food reward.

Hotplate test for thermal sensitivity. Individual mice were placed in a tall plastic cylinder located on a hotplate, with a surface heated to $55^{\circ} \mathrm{C}$ (IITC Life Science). Reactions to the heated surface, including hindpaw lick, vocalization, or jumping, led to immediate removal from the hotplate. Measures were taken of latency to respond, with a maximum test length of $30 \mathrm{~s}$.

Open field test. Exploratory activity in a novel environment was assessed by a $1 \mathrm{~h}$ trial in an open field chamber $(41 \mathrm{~cm} \times 41 \mathrm{~cm} \times 30 \mathrm{~cm})$ crossed by a grid of photobeams (VersaMax system, AccuScan Instruments). Counts were taken of the number of photobeams broken during the trial in $5 \mathrm{~min}$ intervals, with separate measures for locomotion (total distance traveled) and rearing movements. Time spent in the center region of the open field was measured as an index of anxiety-like behavior.

Rotarod. Subjects were tested for motor coordination and learning on an accelerating rotarod (Ugo Basile, Stoelting). For the first test session, animals were given three trials, with $45 \mathrm{~s}$ between each trial. Two additional trials were given $48 \mathrm{~h}$ later. Revolutions per minute (rpm) was set at an initial value of 3 , with a progressive increase to a maximum of 30 rpm across $5 \mathrm{~min}$ (the maximum trial length). Measures were taken for latency to fall from the top of the rotating barrel.

Sociability in a 3-chamber choice test. Mice were evaluated for the effects of Trim 9 deficiency on social preference. The procedure consisted of three 10 min phases: a habituation period, a test for sociability, and a test for social novelty preference. For the sociability assay, mice were given a choice between proximity to an unfamiliar conspecific ("stranger 1") versus being alone. In the social novelty phase, mice were given a choice between the already-investigated stranger 1, versus a new unfamiliar mouse ("stranger 2"). The social testing apparatus was a rectangular, 3-chambered box fabricated from clear Plexiglas. Dividing walls had doorways allowing access into each chamber. An automated image tracking system (Noldus Ethovision) provided measures of time in spent within $5 \mathrm{~cm}$ of the Plexiglas cages (the cage proximity zone) and entries into each side of the social test box.

At the start of the test, the test mouse was placed in the middle chamber and allowed to explore for $10 \mathrm{~min}$, with the doorways into the 2 side chambers open. After the habituation period, the test mouse was enclosed in the center compartment of the social test box, and an unfamiliar, sex-matched C57BL/6J adult (stranger 1) was placed in one of the side chambers. The stranger mouse was enclosed in a small Plexiglas cage drilled with holes, which allowed nose contact but prevented fighting. An identical empty Plexiglas cage was placed in the opposite side of the chamber. Following placement of the stranger and the empty cage, the doors were reopened, and the subject was allowed to explore the entire social test box for a $10 \mathrm{~min}$ session. Measures were taken of the amount of time spent in each cage proximity zone, and the number of entries into each chamber, by the automated tracking system. At the end of the sociability phase, stranger 2 was placed in the empty Plexiglas container, and the test mouse was given an additional $10 \mathrm{~min}$ to explore the social test box. Time spent in cage proximity zones is reported.

Acoustic startle test. This procedure can be used to assess auditory function, reactivity to environmental stimuli, and sensorimotor gating. The test is based on the reflexive whole-body flinch, or startle response, that follows exposure to a sudden noise. Measures are taken of startle magnitude and prepulse inhibition, which occurs when a 
weak prestimulus leads to a reduced startle in response to a subsequent louder noise.

Subjects were given two acoustic startle tests (San Diego Instruments, SR-Lab system): one in week 5 of the behavioral study and one in week 10. Briefly, mice were placed in a small Plexiglas cylinder within a larger, sound-attenuating chamber. The cylinder was seated upon a piezoelectric transducer, which allowed vibrations to be quantified and displayed on a computer. The chamber included a ceiling light, fan, and a loudspeaker for the acoustic stimuli. Background sound levels $(70 \mathrm{~dB})$ and calibration of the acoustic stimuli were confirmed with a digital sound level meter (San Diego Instruments).

Each session consisted of 42 trials that began with a 5 min habituation period. There were 7 different types of trials: the no-stimulus trials, trials with the acoustic startle stimulus $(40 \mathrm{~ms} ; 120 \mathrm{~dB})$ alone, and trials in which a prepulse stimulus ( $20 \mathrm{~ms} ; 74,78,82,86$, or $90 \mathrm{~dB}$ ) occurred 100 $\mathrm{ms}$ before the onset of the startle stimulus. Measures were taken of the startle amplitude for each trial across a $65 \mathrm{~ms}$ sampling window, and an overall analysis was performed for each subject's data for levels of prepulse inhibition at each prepulse sound level (calculated as $100-[($ response amplitude for prepulse stimulus and startle stimulus together/ response amplitude for startle stimulus alone) $\times 100]$.

Morris Water Maze. The water maze consisted of a large circular pool $($ diameter $=122 \mathrm{~cm})$ partially filled with water $\left(45 \mathrm{~cm}\right.$ deep, $\left.24^{\circ} \mathrm{C}-26^{\circ} \mathrm{C}\right)$, located in a room with numerous visual cues. The procedure involved two different phases: a visible platform test and acquisition in the hidden platform task. Two male mice (one Trim $9^{+/+}$and one Trim $9^{-/-}$) were not tested in the water maze, due to injuries from home-cage fighting. One female Trim $9^{-1-}$ mouse failed to swim to the visible platform on 3 of the 4 trials conducted on the second day, and was not tested in the spatial learning procedure.

Visible platform test. Each mouse was given 4 trials per day, across $2 \mathrm{~d}$, to swim to an escape platform cued by a patterned cylinder extending above the surface of the water. For each trial, the mouse was placed in the pool at 1 of 4 possible locations (randomly ordered), and then given $60 \mathrm{~s}$ to find the visible platform. If the mouse found the platform, the trial ended, and the animal was allowed to remain $10 \mathrm{~s}$ on the platform before the next trial began. If the platform was not found, the mouse was placed on the platform for $10 \mathrm{~s}$ and then given the next trial. Measures were taken of latency to find the platform and swimming speed via an automated tracking system (Noldus Ethovision).

Acquisition in a hidden platform task. Following the visible platform task, mice were tested for their ability to find a submerged, hidden escape platform (diameter $=12 \mathrm{~cm}$ ). Each animal was given 4 trials per day, with $1 \mathrm{~min}$ per trial, to swim to the hidden platform. Criterion for learning was an average group latency of $\leq 15$ s to locate the platform. Mice were tested until the group reached criterion, with a maximum of $9 \mathrm{~d}$ of testing. When criterion was reached, mice were given a $1 \mathrm{~min}$ probe trial in the pool with the platform removed. Quadrant selectivity, an index of spatial learning, was evaluated by measuring number of crossings over the location where the platform (the target) had been placed during training, versus the corresponding area in the other three quadrants.

Statistics. At least three independent experiments were performed for each assay. Data distribution normality was determined using the Shapiro-Wilkes test. Normally distributed data were compared by unpaired $t$ test, for two independent samples, or ANOVA with Holm-Sidek $(>5$ comparisons) or Bonferroni ( $>2,<5$ comparisons) post hoc correction, For non-normal data, the Mann-Whitney test was used or KruskalWallis nonparametric ANOVA with Bonferonni post hoc correction for $>2$ comparisons. All data are presented as mean \pm SEM.

\section{Results}

TRIM9 is expressed in the embryonic and adult murine hippocampus

Based on evolutionary conservation, presence and function in developing neurons, and a possible role in human neuropathology, we hypothesized that TRIM9 functioned in establishing or maintaining hippocampal neuron morphology and connectivity.
Previous studies suggested that TRIM9 was expressed in the hippocampus, although RNA probe and antibody specificity were not confirmed in Trim $9^{-1-}$ samples (Li et al., 2001; Berti et al., 2002; Tanji et al., 2010). We reported the generation of a conditional Trim 9 allele (Trim $9^{f l}$ ) and germline deletion of murine Trim9 using CMV-Cre Trim9 ${ }^{-1-}$ (Winkle et al., 2014). In lysate prepared from embryonic day 15.5 (E15.5) Trim $^{+/+}$hippocampus, three expected TRIM9 isoforms were observed, which were absent from E15.5 Trim $^{-/-}$hippocampus (Fig. 1A). Similarly, TRIM9-immunoreactive bands were present in adult Trim $9^{+/+}$ hippocampus, but not Trim $9^{-1-}$ hippocampus (Fig. $1 A$ ). To further confirm the specificity of TRIM9 antibodies, lysate was immunoprecipitated with antibodies raised against $\mathrm{NH} 2$-terminal BBox domains of TRIM9 (Winkle et al., 2014) and probed with antibodies raised against the $\mathrm{COOH}$ terminus of human TRIM9 (Tanji et al., 2010). Immunoprecipitation enriched TRIM9immunoreactive bands in Trim $9^{+/+}$hippocampus, but not in Trim $9^{-1-}$ hippocampus (Fig. $1 A$ ). Immunohistochemistry of coronal sections through the hippocampus of adult littermates revealed TRIM9 immunoreactivity throughout the intact hippocampus of $\mathrm{TRIMO}^{+/+}$mice, including the CA1 and DG, whereas Trim $9^{-1-}$ animals exhibit only nonspecific background immunoreactivity (Fig. $1 B, C$ ). Thus, TRIM9 is present in both the developing and adult murine hippocampus and absent from the hippocampus of Trim $9^{-1-}$ animals.

\section{TRIM9 interacts and colocalizes with the netrin-1 receptor DCC in hippocampal neurons}

TRIM9 directly interacts with the netrin receptor DCC, and these proteins colocalize in embryonic mouse cortical neurons (Winkle et al., 2014). To characterize the localization of TRIM9 and DCC in hippocampal neurons, we introduced fluorescently tagged TRIM9 and DCC into dissociated hippocampal neurons and performed live cell total internal reflection fluorescence imaging (Fig. 2A). mCherry-TRIM9 and DCC-pHluorin exhibited moderate colocalization (Pearsons coefficient $0.34 \pm 0.052$ ), which was greater than that observed upon scrambling of DCCpHluorin images $(0.0008, p<0.01)$. Such colocalization is detected in the shafts of neurites and the tips of branches (Fig. $2 \mathrm{~A}$, zoomed insets). To determine whether endogenous TRIM9 and DCC interact, we performed coimmunoprecipitation. Immunoprecipitation with DCC or TRIM9-specific antibodies coprecipitated TRIM9 or DCC, respectively, from Trim $9^{+/+}$but not Trim9 ${ }^{-1-}$ E15.5 hippocampal lysate (Figure $2 B$ ). Similarly, immunoprecipitation with DCC antibodies coprecipitated TRIM9 from Trim $9^{+/+}$, but not Trim $9^{-/-}$adult hippocampus (Fig. 2C). Although relatively low amounts of coimmunoprecipitated protein were observed in either embryonic or adult hippocampal lysate, this is typical of interactions with E3 ubiquitin ligases (Kim et al., 2015).

\section{Deletion of Trim 9 increases hippocampal dendritic and axonal complexity in vitro}

TRIM9 regulates the branching and guidance of axons of developing murine cortical neurons (Winkle et al., 2014; Menon et al., 2015) and in invertebrates (Hao et al., 2010; Morikawa et al., 2011; Morf et al., 2013). TRIM9 is present in cultured hippocampal neurons, where its expression increases over time in vitro (Fig. $3 A$ ). Thus, we examined whether loss of Trim 9 affected the stereotypical morphological progression of hippocampal neurons (Dotti et al., 1988) (Figure 3A). At 1 and 2 DIV, more Trim9 ${ }^{-1-}$ hippocampal neurons had initiated neurites and an axon, characteristics of later-stage polarized neurons, compared with 

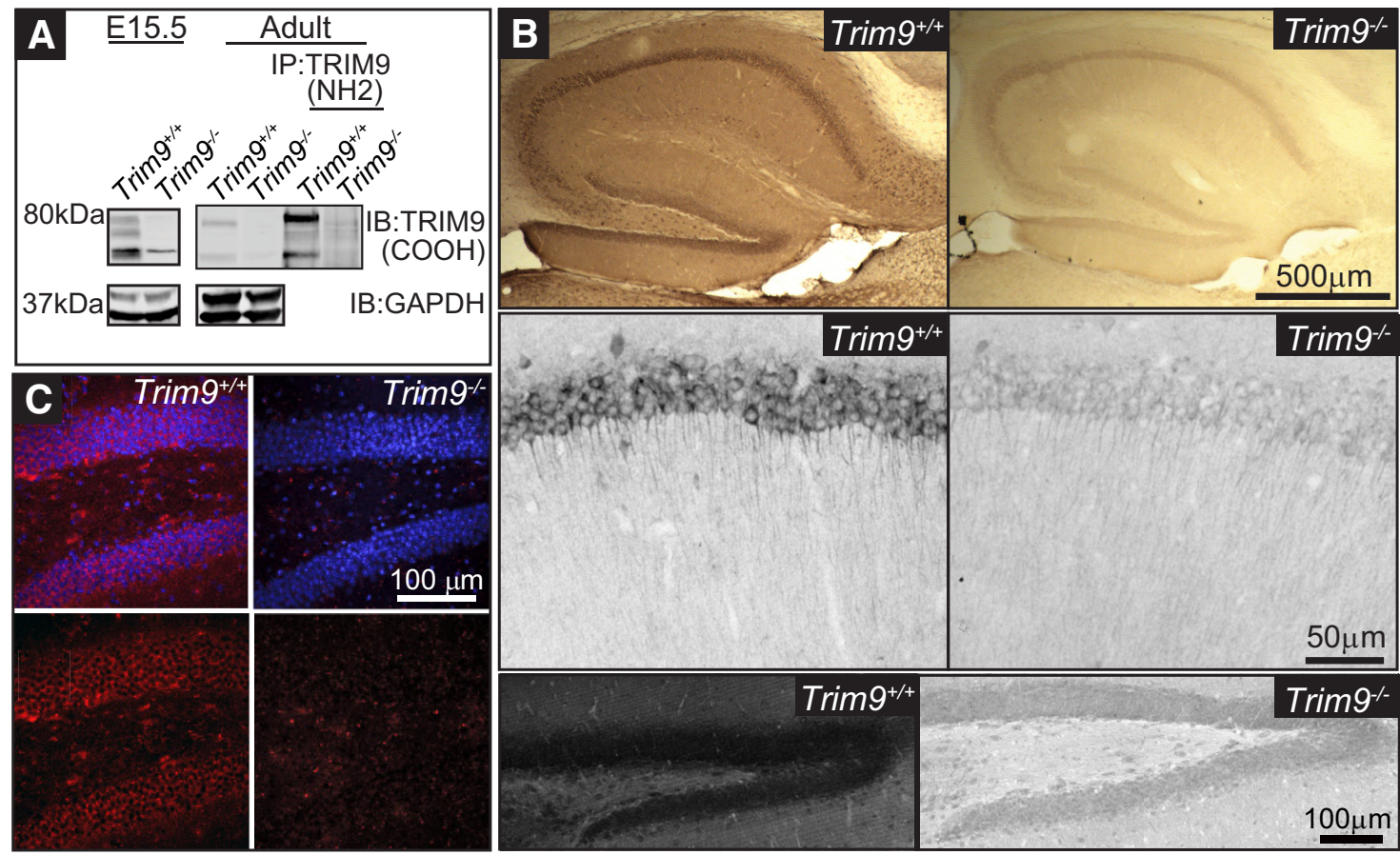

Figure 1. TRIM9 is expressed in the embryonic and adult hippocampus. A, Western blot of hippocampal lysate from Trim $9^{+/+}$and Trim $9^{-/-}$embryonic day 15.5 (E15.5) mice (left), showing the immunoreactivity of the three splice variants of TRIM 9 present in Trim $9^{+/+}$samples but absent from Trim $9^{-1-}$ samples. GAPDH shown as loading control. Western blot of inputs and TRIM9 immunoprecipitated from adult hippocampal lysate from $\operatorname{Trim} 9^{+/+}$and $\operatorname{Trim} 9^{-/-}$mice (right). TRIM9 was precipitated with antibodies that recognized the NH2 terminal BBox domains of TRIM9, and probed with antibodies raised against the $\mathrm{COOH}$ terminus of TRIM9. GAPDH shown as loading control for inputs (first 2 lanes). $\boldsymbol{B}$, DAB immunohistochemistry showing immunopositivity for TRIM9 in the hippocampus of adult Trim $9^{+/+}$but not Trim $9^{-/-}$mice. Zoomed images demonstrate TRIM9 expression in the CA1 (middle) and DG (bottom) of adult Trim $9^{+/+}$mice, but not Trim $9^{-/-}$mice. C, Fluorescent immunohistochemistry showing immunopositivity for TRIM9 in the DG of adult Trim $9^{+/+}$mice, but not Trim $9^{-/-}$mice. Red represents TRIM9. Blue represents DAPI.

Trim $9^{+/+}$neurons $(p<0.005$ for 1 DIV, $p<0.01$ for 2 DIV). This suggests that the loss of Trim 9 accelerates neuronal morphogenesis (Fig. 3B-E). Because TRIM9 and DCC interact and colocalize in hippocampal neurons, we tested netrin responses. Bath application of netrin-1 accelerated neuronal morphogenesis in Trim $9^{+/+}$neurons $(p<0.05)$ but did not further accelerate morphological progression of Trim $9^{-1-}$ neurons (Fig. 3B-E).

After establishing a polarized neuronal morphology, the presumed axon (longest neurite) and dendrites extend and ramify, which increases the synaptic capacity of the neuron (Stage 4-5; Fig. $3 A$ ). We compared the length and branching of axons and dendrites at 3 and 5 DIV (Fig. $3 C-E$ ). The overall number and length of neurites were unchanged by loss of Trim9. However, Trim $9^{-1-}$ hippocampal neurons exhibited increased density of branching of both the axon and the remaining neurites at 3 DIV ( $p<0.0001$ for both axons and dendrites). This continued at 5 DIV, when Trim $9^{-1-}$ neurons exhibited a higher density of secondary and tertiary dendritic branching $(p<0.0001$ for both axons and dendrites). The $24 \mathrm{~h}$ bath application of netrin- 1 increased the density of axonal and dendritic branches at 3 DIV in Trim $9^{+/+}(p<0.01$ for both axons and dendrites), whereas only axon branching density increased following netrin- 1 treatment in Trim $9^{-1-}$ neurons $(p<0.005)$. Bath application of netrin-1 for $24 \mathrm{~h}$ before fixation at 5 DIV only increased the density of tertiary dendrites and secondary axon branches in Trim $9^{-1-}$ hippocampal neurons ( $p<0.001$ for both; Fig. $3 E$ ). These differences suggest that TRIM9 normally restrains the acquisition of neuronal complexity, which allows for a netrin-dependent promotion of morphogenesis.
Expression of full-length TRIM9 rescues aberrant arborization in Trim $9^{-/-}$neurons

To confirm the aberrant dendritic and axonal arborization were due to loss of TRIM9, we introduced Myc-TRIM9 expression plasmids into Trim $9^{-1-}$ hippocampal neurons and assessed arborization at 3 DIV (Fig. 4). Myc-TRIM9 expression decreased constitutive dendritic and axonal arborization to wild-type levels and restored netrin- 1 sensitivity $(p<0.0001)$, thereby rescuing aberrant arborization in Trim $9^{-1-}$ neurons. To assess the role of TRIM9 ligase activity, we introduced MycTRIM9 $\Delta$ RING, which lacks the ubiquitin ligase RING domain (Winkle et al., 2014). MycTRIM9 $\Delta$ RING reduced the aberrant constitutive axonal and dendritic arborization of Trim $9^{-1-}$ neurons (Fig. $4 ; p<0.0005$ for both) but failed to restore sensitivity to netrin-1. Expression of a TRIM9 variant that lacks the DCC binding domain, MycTRIM9 $\Delta$ SPRY, reduced elevated arborization (Fig. $4 ; p<$ $0.0005)$, but similarly failed to restore netrin-1 sensitivity. These data suggest that TRIM9 restrains morphogenesis of hippocampal neurons and that TRIM9 ligase activity and binding to DCC are necessary for netrin-1-dependent morphogenesis.

\section{Deletion of Trim9 is associated with dendritic and axonal defects in vivo}

To determine whether arborization defects also occurred in vivo in the absence of Trim 9 , we crossed Trim $9^{-1-}$ mice with Thy1GFP mice (line M), which express GFP in a subset of hippocampal neurons (Feng et al., 2000). Extensive overlapping dendritic arbors of GFP-expressing $\left(\mathrm{GFP}^{+}\right)$neurons at P21 prohibited tracing of individual dendrites; we therefore compared the area of $\mathrm{GFP}^{+}$dendritic material in a ROI in the molecular layer encom- 
passing dendritic termination points, relative to the number of $\mathrm{GFP}^{+}$soma in the CA3 GCL. This revealed that Thy1-GFP/ Trim $9^{-1-}$ hippocampal neurons had increased dendritic material compared with Thy1-GFP/Trim9 ${ }^{+/+}$littermates (Fig. 5A; $p<0.05)$, with no changes in the percentage of $\mathrm{GFP}^{+}$neurons $(14.1 \pm 2.1 \%$ vs $15.4 \pm 0.8 \%)$.

A subset of CA3 pyramidal cells project to the septal nuclei (Gaykema et al., 1991; Witter, 2007), and this projection is disrupted by netrin-1 deficiency (Barallobre et al., 2000). To determine whether deletion of Trim9 also disrupted this projection, we used NEX-Cre/Tau-LoxP-STOP-LoxPmGFP mice (Goebbels et al., 2006) crossed with Trim $9^{f l / f l}$ mice. The NEX promoter drives Cre expression in postmitotic, excitatory neocortical and hippocampal neurons, and is not detectably expressed in neurons originating in the septum (Gong et al., 2003; Goebbels et al., 2006), thus allowing expression of mGFP and deletion of Trim 9 when the relevant alleles are present. Although no gross anatomical defects were apparent in the hippocampus (Figs. $1 B, C, 5 B$ ), we observed a $20 \pm 6.5 \%$ increase in the area containing $\mathrm{GFP}^{+}$fibers in the septal nuclei of NEX-Cre/Tau-LoxP-STOPLoxP-mGFP/Trim $9^{f l f l}$ mice compared with NEX-Cre/Tau-LoxP-STOP-LoxPmGFP/Trim $9^{+/+}$littermates (Fig. $5 C ; p=$ $0.035)$. Increased axonal material within the septal nuclei may originate from misguided axons and/or elevated axonal branching, as we have previously observed in the corpus callosum of Trim $9^{-1-}$ mice (Winkle et al., 2014). Although increased axonal material is likely due to changes in the hippocampal projections that normally innervate the septal nuclei, a possible contribution of neocortical $\mathrm{GFP}^{+}$fibers misprojecting into this area is not ruled out. However, these data are consistent with the hypothesis that morphology defects observed in Trim $9^{-1-}$ hippocampal neurons in vitro impact circuit assembly in vivo.

\section{Deletion of Trim9 causes somal mislocalization of adult-born hippocampal neurons}

As the analysis of neuronal morphology in the adult brain was complicated by the complex, overlapping processes of hippocampal neurons and the high level of neuronal labeling in reporter mice, we sought another method to investigate the morphology of hippocampal neurons in vivo. Because TRIM9 is present in the adult hippocampus where neurogenesis and morphogenesis occur, we investigated whether deletion of Trim 9 affected the development of adult-born DG neurons and their incorporation into local circuitry. Stereotaxic introduction of GFP-containing retrovirus into the DG was used to sparsely label and birth date newly born neurons, allowing for comparison of their placement and morphology in vivo. Consistent with findings that TRIM9 mRNA is enriched in maturing adult-born neurons relative to mature counterparts (Chatzi et al., 2016), these $\mathrm{GFP}^{+}$adult-born neurons were immunopositive for TRIM9

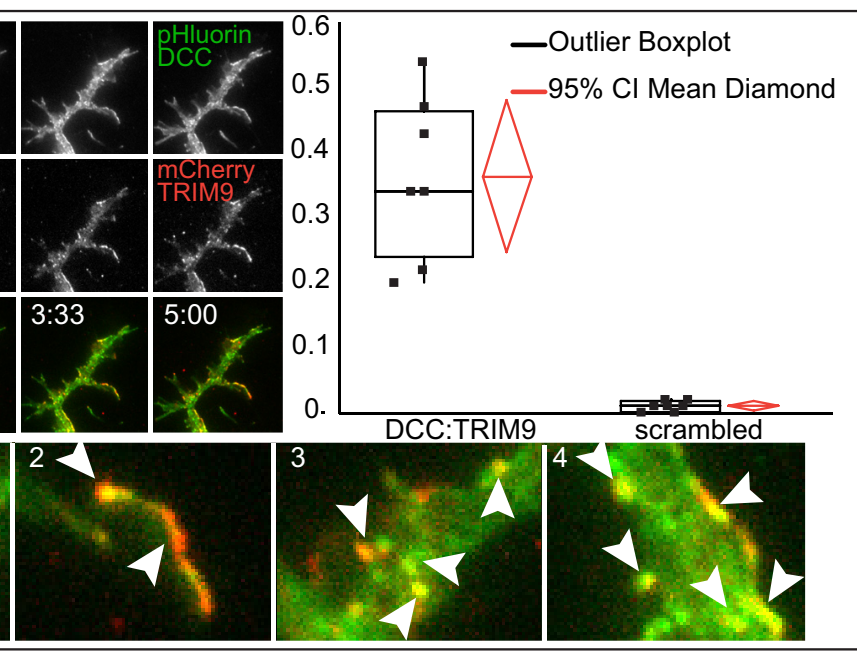

C Adult Hippocampus

Input IP:DCC IP:Goat IgG

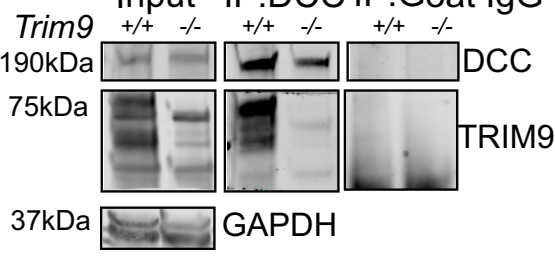

$37 \mathrm{kDa}$ GAPDH

Figure 2. TRIM9 colocalizes and interacts with the netrin-1 receptor DCC in hippocampal neurons. $\boldsymbol{A}$, Hippocampal neurons at mCherry-TRIM9 and DCC-pHlourin showing colocalization along the neurite shaft, and at the tips of branches DCC-pHluorin $(n=7$ neurons, mean colocalization $=0.34)$. $\boldsymbol{B}$, Western blot of DCC and TRIM9 immunocomplexes precipitated coimmunoprecipitated by TRIM 9 antibodies in Trim $9^{+/+}$but not Trim $9^{-1-}$ samples. C, Western blot of immunoprecipitates shows the splice variants of TRIM9 coimmunoprecipitated by DCC antibodies in Trim $9^{+/+}$but not Trim $9^{-1-}$ samples. Goat lgG precipitations shown as a negative control. GAPDH is shown as a loading control.

(Fig. 6A), suggesting that TRIM9 is expressed in these cells during their maturation. Comparison of $\operatorname{Trim} 9^{+/+}$and $\operatorname{Tr} i m 9^{-/-}$littermates revealed unusual localization of adult-born neurons in Trim $9^{-1-}$ mice. Whereas newborn neurons generally reside in the inner GCL at 14 days post injection (DPI) (Fig. 6B-D), retroviral-labeled $\mathrm{GFP}^{+}$adult neurons in the DG were mislocalized in Trim $9^{-1-}$ animals $(p<0.0001$; Fig. 6C,D). An increased percentage of Trim $9^{-1-}$ neurons localized within the middle third of the GCL $(p<0.0001)$ and the hilar region $(p=0.0076)$, with a reduced proportion of TRIM9 ${ }^{-1-}$ neurons in the appropriate inner third region of the GCL ( $p<0.0001$; Fig. $6 D)$. To decipher whether this improper localization could be due to misplaced neural stem cells or aberrant migration of progenitors and immature neurons, we stained retrovirus naive tissue in Trim $9^{-1-}$ mice for nestin, a stem cell marker, and DCX, an immature neuronal marker. Nestin ${ }^{+}$stem cells resided within the SGZ as expected (Fig. 6E). Although most $\mathrm{DCX}^{+}$cells resided normally in the SGZ and inner GCL, a subset of DCX ${ }^{+}$immature neurons or neuroblasts were present in the middle region of the GCL and in the hilus (Fig. 6E). These data are consistent with aberrant migration of neuroblasts and/or immature neurons, rather than misplaced stem cell populations. Further, costaining with Prox1, a granule cell marker, confirmed the identity of mislocalized $\mathrm{GFP}^{+}$cells as maturing granule cells (Fig. $6 \mathrm{~F}$ ), suggesting mislocalized Trim $9^{-1-}$ adult-born cells continue maturation along the granule-cell lineage. 


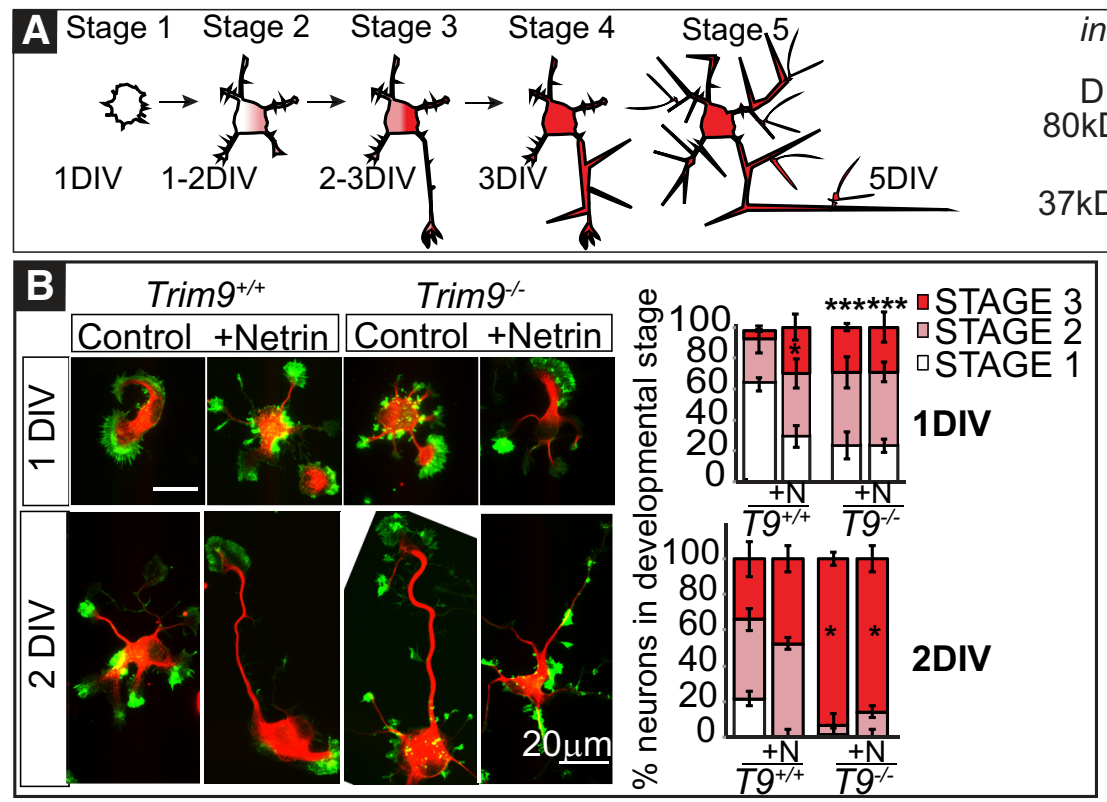

C

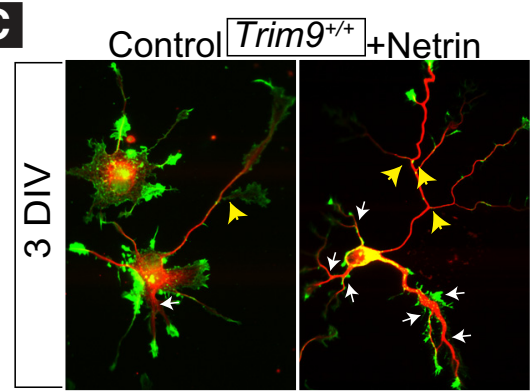

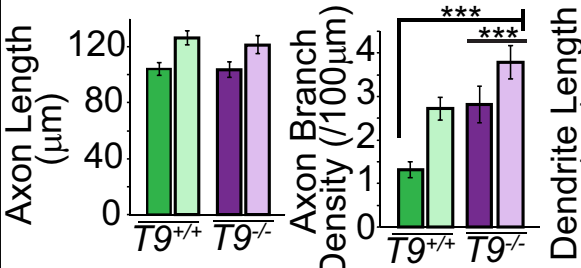
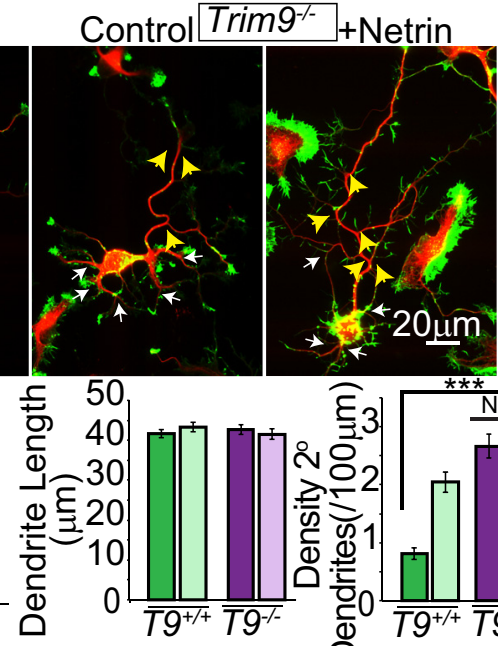

Eิ $\frac{* \star \pi}{N . S !}$

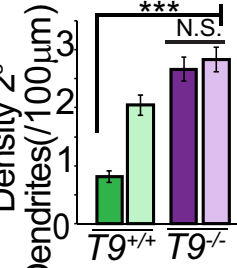

D

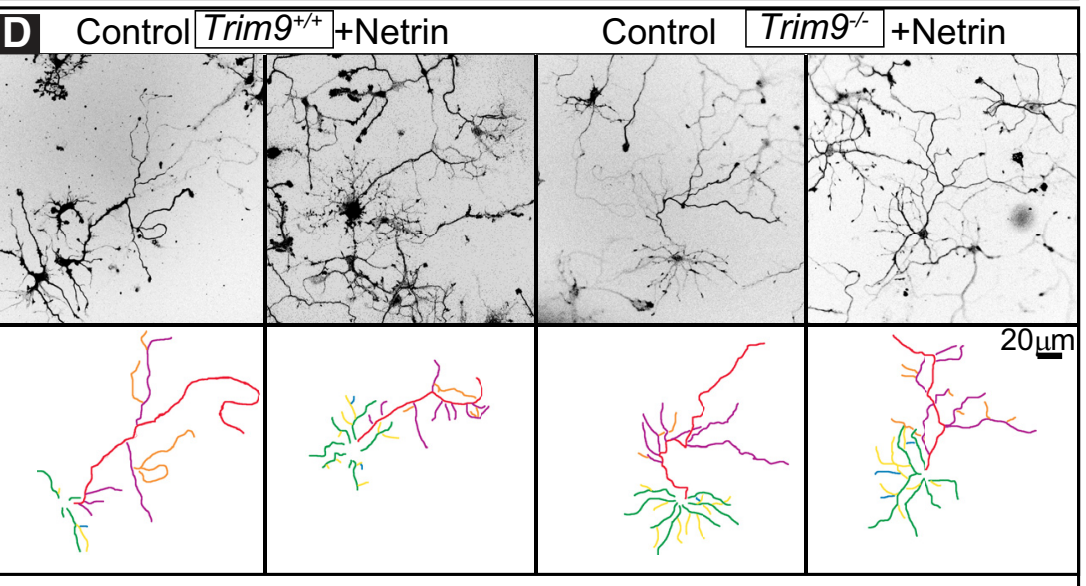

in vitro $\quad$ Trim $9^{+/+}$

DIV $122 \quad 3 \quad 5 \quad 14$

80kDa $=2 \mathrm{IB}:$ TRIM9

$37 \mathrm{kDa}$

$=-\approx \mathrm{IB}: \mathrm{GAPDH}$
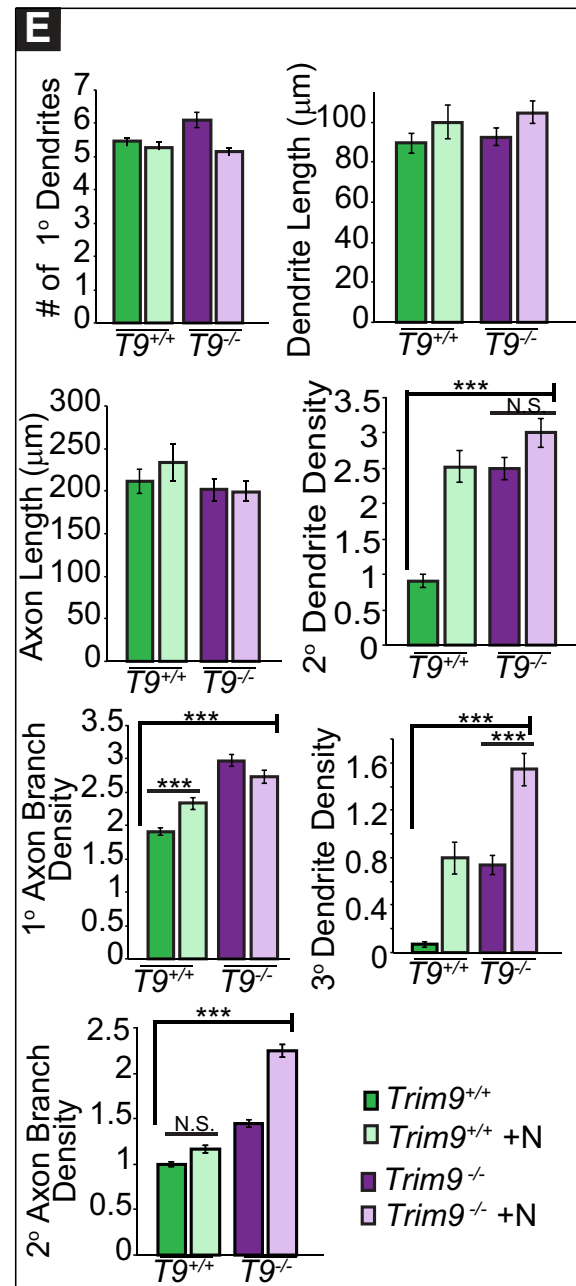

पTrim $9^{+/+}$

$\mathrm{T} \operatorname{Trim} 9^{+/+}+\mathrm{N}$

Trim $9^{-1}$

口 $\operatorname{Trim} 9 \%+\mathrm{N}$

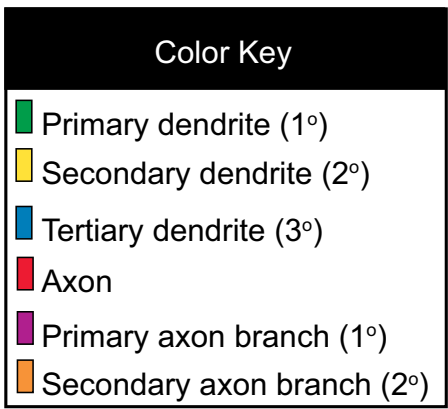

Figure 3. Deletion of Trim 9 results in increased dendritic arborization and axon branching in vitro. $A$, Graphical representation of neuronal stages of morphology. Stage 1 neurons lack neurites. Stage 2 neurons have 1 or more neurites. Stage 3 neurons have a presumed axon at least 2 times the length of other neurites. Axonal and dendritic branches emerge in Stage 4 and Stage 5 neurons, respectively. Western blot of TRIM9 in E15.5 hippocampal neurons in vitro over time. B, Immunofluorescence of Trim $9^{+/+}\left(\mathrm{T}^{+/+}\right)$and $\operatorname{Trim}^{-/-}\left(\mathrm{T}^{-/-}\right)$dissociated hippocampal neurons at 1 and 2 DIV and quantifications of percentage of total cells per developmental stage, \pm SEM from three independent experiments. C, Immunofluorescence of Trim $9^{+/+}$and Trim ${ }^{-/-}$dissociated hippocampal neurons at $3 \mathrm{DIV}$ and quantifications of average length $(\mu \mathrm{m})$, average number of neurites, and average branches $/ 100 \mu \mathrm{m}$ primary neurite length at $3 \mathrm{DIV}$. Red represents $\beta I I I-t u b u l i n$. Green represents F-actin (phalloidin). White arrows indicate secondary dendrite branches. Yellow arrows indicate axon branches. D, Immunofluorescence and color-coded tracings of Trim $9^{+/+}$and $\operatorname{Trim} 9^{-1-}$ dissociated hippocampal neurons at 5 DIV. Images have been inverted from a grayscale merged F-actin and $\beta$ III-tubulin image. $\boldsymbol{E}$, Quantifications of average length ( $\left.\mu \mathrm{m}\right)$, average number of neurites, and average branches $/ 100 \mu \mathrm{m}$ primary neurite length for 5 DIV. Error bars indicate SEM. ${ }^{*} p<0.05 .{ }^{* *} p<0.005 .{ }^{* * *} p<0.0005$. NS, Not significant. 

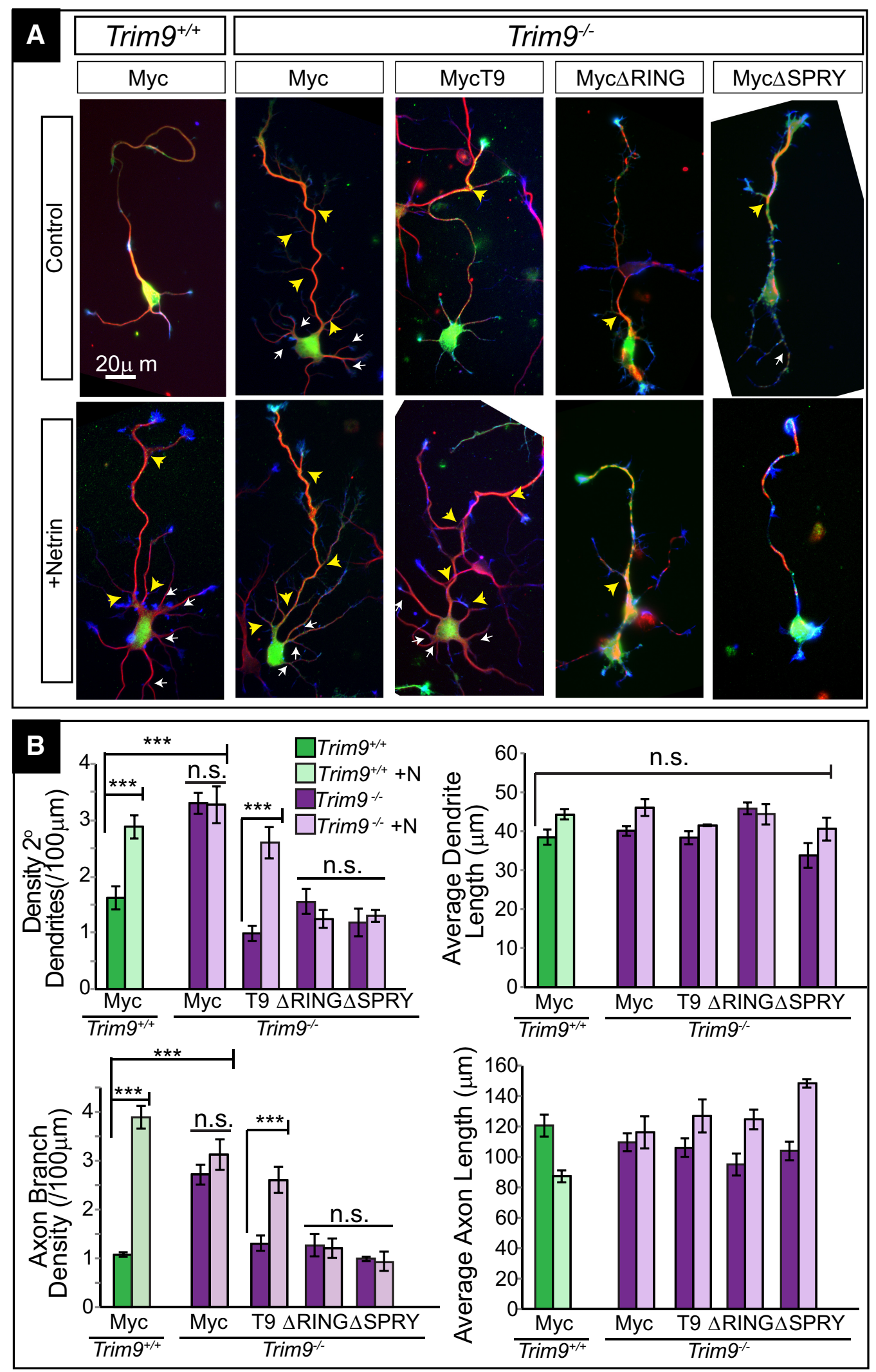

Figure 4. Expression of full-length TRIM9 rescues aberrant arborization in Trim $9^{-/-}$hippocampal neurons. $A$, Immunofluorescence of Trim $9^{+/+}$and Trim $9^{-1-}$ dissociated hippocampal neurons transfected with Myc and Myc tagged variants of TRIM9 at 3 DIV. T9 indicates full-length TRIM9. $\triangle$ RING and $\triangle$ SPRY represent TRIM9 lacking the RING domain and SPRY domain, respectively. Red represents $\beta$ III-tubulin. Green represents Myc. Blue represents F-actin (phalloidin). White arrows indicate secondary dendrite branches. Yellow arrows indicate axon branches. $\boldsymbol{B}, \mathbf{Q}$ uantifications of average branches $/ 100 \mu \mathrm{m}$ primary neurite length and average length $(\mu \mathrm{m})$ at 3 DIV. Error bars indicate SEM. ${ }^{* * *} p<0.0005$. n.s., Not significant. 

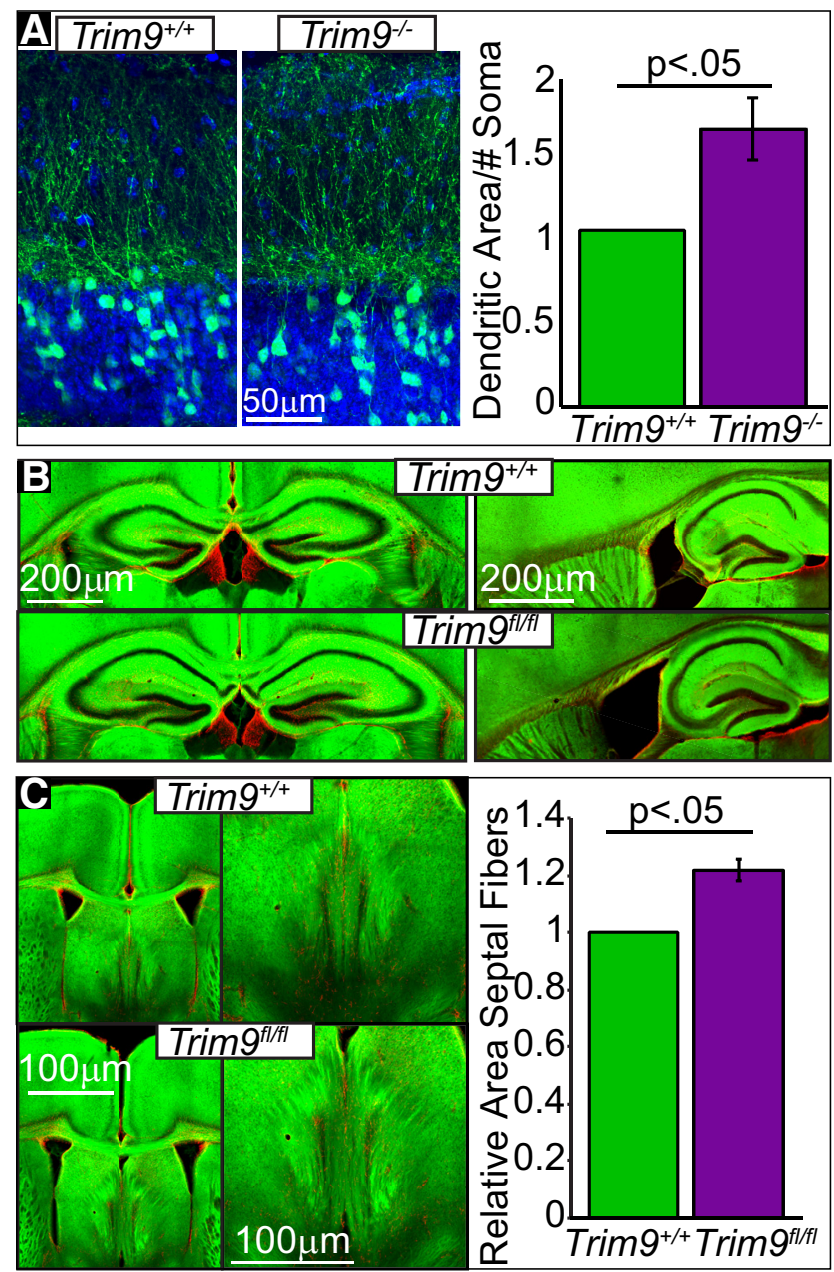

Figure 5. Deletion of Trim 9 in vivo increases dendritic arborization and increases axonal material in the septal nuclei. $A, C A 3$ ROls containing the cell bodies and molecular layer extending to dendritic termini from 3-week-old Thy1-GFP littermate in the hippocampus. Blue represents DAPI-stained nuclei. Green represents Thy1-GFP-positive neurons. Quantification of $\mathrm{GFP}^{+}$dendritic area relative to the number of GFP ${ }^{+}$soma in the ROI ( $n=3$ littermate pairs). $B$, Hippocampal sections in coronal (left) and sagittal (right) planes of 5-week-old NEX-Cre/

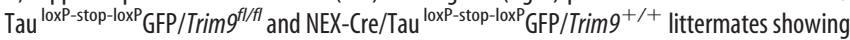
no major neuroanatomical defects. C, Coronal image z-projections of 5-week-old NEX-Cre/

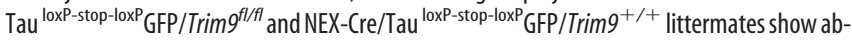

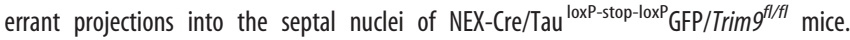
Quantification of the relative area of septal axonal projections. Red represents GFAP-staining. Green represents GFP. $p<0.05$.

Deletion of Trim9 results in increased dendritic complexity in adult-born neurons.

To determine whether the hyperarborization of dendrites seen in vitro and at early postnatal time points in vivo occurred in adultborn neurons, we analyzed dendritic arborization patterns of $\mathrm{GFP}^{+}$adult-born neurons at 14 DPI (Fig. 7). Both Trim $9^{+/+}$and Trim $9^{-1-}$ neurons exhibited typical increases in dendritic branching with distance from the soma $\left(F_{(15,60)}=25.69, p<\right.$ 0.0001 , insignificant interaction with genotype); however, the complexity was elevated in the Trim $9^{-1-}$ neurons $\left(F_{(1,4)}=12.50\right.$, $p=0.0241)$, with greater branch crossings in the Trim $9^{-1-}$ mice (Fig. $7 B$ ). Despite increased cumulative dendritic crossings at 80 $\mu \mathrm{m}$ and onward in the Trim $9^{-1-}$ group (Fig. $7 C$, asterisks), the difference in the pattern of branching (cumulative crossings) only approached significance (Kolmogorov-Smirnov, $\mathrm{D}=$
0.4375, $p=0.0935$; Fig. $7 C$ ), indicating that $\operatorname{Trim} 9^{+/+}$and Trim $9^{-I-}$ dendrites branched at similar points along the dendrite. Complexity of branching was increased in the Trim $9^{-1-}$ dendrites (total number of branches, $p=0.0008$; highest branch order, $p=0.005$; a trend toward an increase in secondary branches, $p=0.0699$; Fig. $7 D-F)$. Similar to embryonic neurons in vitro, the length of the longest (primary) dendrite was not different between genotypes (Fig. $7 G$ ). These results largely recapitulate our in vitro data and indicate that TRIM9 regulates the density and complexity of dendritic arbors in adult-born neurons in vivo.

Deletion of Trim9 results in increased thickness of the initial dendrite and reduced dendritic spine density.

In addition to more complex dendritic trees at 14 DPI, the diameter of the initial dendritic segment arising from the soma and extending to the first branch point at 28 DPI was thicker in Trim $9^{-1-}$ mice compared with littermates $\left(\operatorname{Trim} 9^{+/+}\right.$vs Trim $9^{-1-} ; 2.19 \pm 0.01 \mu \mathrm{m}^{2}$ vs $3.17 \pm 0.32 \mu \mathrm{m}^{2} ; p=0.037$; Fig. $8 A)$. These changes were not associated with a significantly decreased distance between the soma and the initial dendritic branch point (Fig. 8B; Trim $9^{+/+}$vs $\operatorname{Trim}^{-/-}$; $34.55 \pm 3.19 \mu \mathrm{m}$ vs $24.40 \pm 3.73 \mu \mathrm{m}, p=0.107)$. To determine whether Trim 9 deletion affected dendritic spine morphogenesis, we investigated spine architecture at $28 \mathrm{DPI}$, when synaptogenesis is occurring (Fig. 8C). Analysis of 3D renderings of dendritic volumes (Fig. $8 D$ ) demonstrated that Trim $9^{-1-}$ neurons exhibited reduced density of dendritic spines (Fig. $8 C, D ; t_{(4)}=2.864, p=0.0458$ ), without alteration in the proportion of spine subtypes. Dendritic spine development contributes to the initiation of the local dendritic spikes (Spruston, 2008), suggesting that the morphological defects associated with deletion of Trim 9 may disturb synaptic inputs to the local circuit.

Disruptions in axonal targeting of DG neurons or placement of CA1 neurons were not detected in the absence of Trim9 Inspection of retrovirally labeled $\mathrm{GFP}^{+}$adult-born DG neurons at $28 \mathrm{DPI}$ demonstrated that their axons projected appropriately to CA3 (Fig. 9A, arrowheads). Because embryonic hippocampal neurons demonstrated excessive axon branching in the absence of Trim9 in vitro (Fig. 3), we scored $\mathrm{GFP}^{+}$axons for axonal protrusions, which often represent axon branch precursors (Spillane et al., 2011; Winkle et al., 2014). The densities of protrusions on both Trim $9^{+/+}$and Trim $9^{-1-}$ axons were not normally distributed, as a subset of axonal segments did not contain such protrusions, and a subset did. As such, comparison of per animal averages was misrepresentative. Therefore, observations were pooled (Fig. 9B); compilation of data by genotype suggested an increased density of axonal protrusions occurred in the absence of Trim9 (Fig. 9B; Trim $9^{+/+}$vs Trim $9^{-1-} ; 0.79 \pm 0.1$ protrusion per $100 \mu \mathrm{m}$ vs $1.19 \pm 0.1$ per $100 \mu \mathrm{m}$, Mann-Whitney nonparametric comparison, $p=0.014$ ).

Because both Trim $9^{-1-}$ embryonic and adult-born neurons exhibited similar arborization defects, we hypothesized that the somal mislocalization observed in a subset of adult-born DG neurons may also occur in developmentally generated Trim $9^{-1-}$ hippocampal neurons. To assess whether Trim 9 deletion produced somal mislocalization outside the DG, we virally labeled neurons in the pyramidal layer of CA1 with CaMKII-mCherry (Fig. 9C) (Wenzel et al., 2001). The pyramidal cell layer in CA1 contains a densely packed band of principle cells generated during development and importantly does not exhibit adult neurogenesis. Mislocalized mCherry ${ }^{+} \mathrm{CA} 1$ pyramidal-shaped neurons 

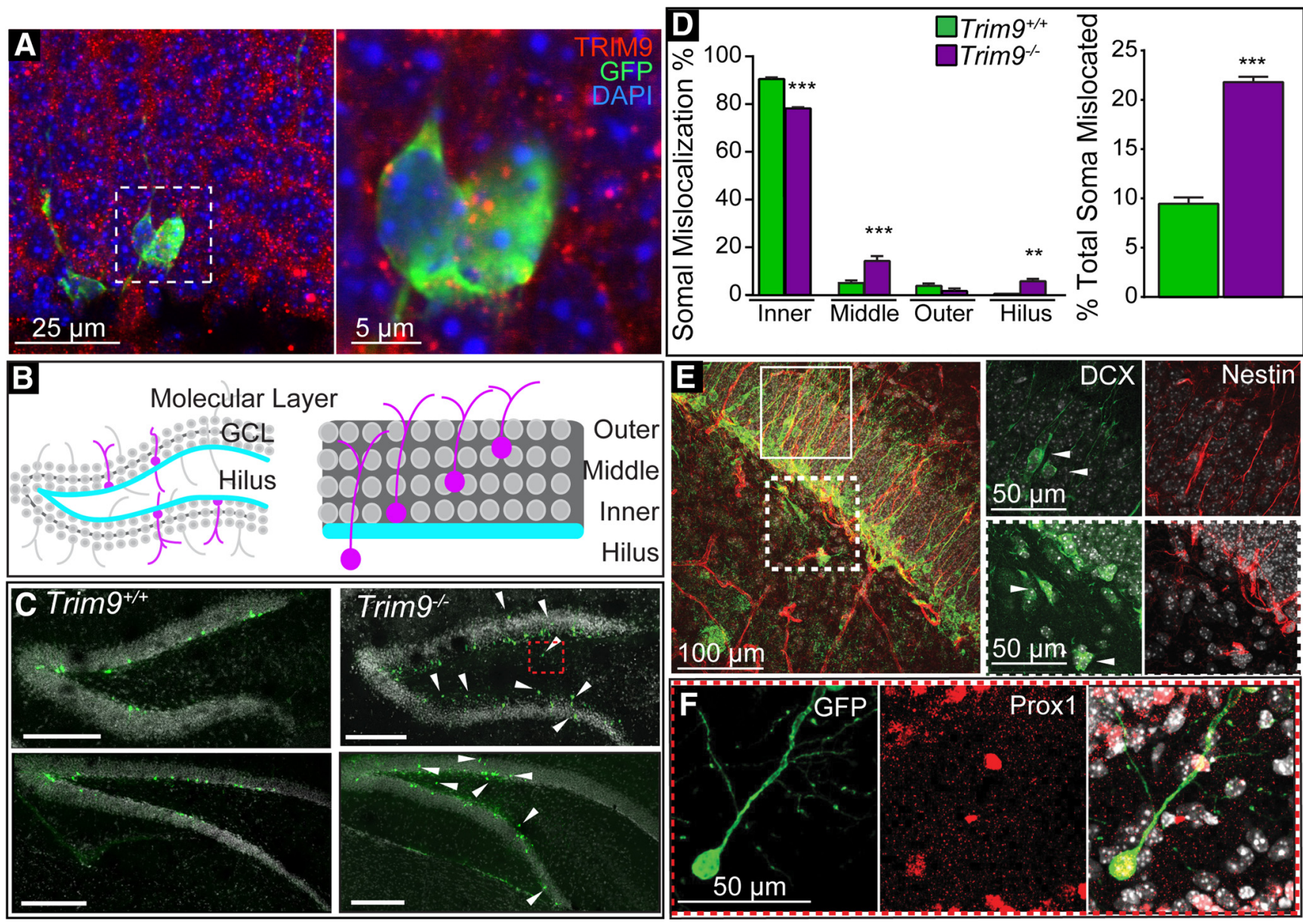

Figure 6. Loss of Trim 9 increases somal mislocalization of newly born neurons in the hippocampus. A, GFP ${ }^{+}$newly born neurons and surrounding mature granule cells are immunoreactive for TRIM9 in Trim $9^{+/+}$adult brains. Immunostaining for TRIM9 (red), GFP (green), DAPI (blue). B, Diagram of DG anatomy and schematic of domains where retrovirally infected GFP ${ }^{+}$adult-born neurons (magenta) were located. $C$, Representative images showing localization of adult-born neuron soma (green) in the DG at $14 \mathrm{DPl}$ of Trim $9^{+/+}$and $\operatorname{Trim}^{9^{-/-}}$mice. White arrowheads indicate outer granule cell layer and hilar-located newborn neurons in Trim $9^{-1-}$ mice. Red inset, High magnification of a hilar-located newborn neuron at 14 DPI shown in $\boldsymbol{F}$. Scale bars $=200 \mu \mathrm{m}$. $\boldsymbol{D}$ Quantification of somal localization. A significantly greater number of Trim $9^{-1-}$ neurons mislocalized to the middle $\mathrm{GCL}(p<0.001)$ and, strikingly, to the hilus $(p<0.01)$, whereas a greater percentage of Trim $9^{+/+}$neurons localized appropriately to the inner $\mathrm{GCL}(p<0.001)$. The total number of mislocalized newborn neurons was significantly elevated compared with Trim $9^{+/+}$ $(p<0.001) . E$, Images and zoomed images denoted by insets of nestin ${ }^{+}$neural stem cells (red) and DCX ${ }^{+}$neuroblasts and immature neurons (green) in the DG. Solid inset, DCX ${ }^{+}$cells mislocated in the middle $\mathrm{GCL}$. Nestin ${ }^{+}$stem cells are correctly localized in the $\mathrm{GCL}$. Dashed inset, $\mathrm{DCX}{ }^{+}$cells localized to the hilar region, where nestin ${ }^{+}$cells are absent. $\boldsymbol{F}$, The GFP ${ }^{+}$neuron (green; $\boldsymbol{C}$ ) is positive for the granule cell marker Prox1 (red). ${ }^{* *} p<0.01 .{ }^{* *} p<0.001$.

were not observed in $\operatorname{Trim} 9^{+/+}$or $\operatorname{Trim} 9^{-/-}$littermates (Fig. 9C, insets). This is consistent with our observations from earlier analyses (Thyl-GFP, Golgi staining), where we did not observe heterotopic cell placements in regions such as CA1 (data not shown). Finally, we found that the thickness of the CA1 pyramidal cell layer as measured across the dorsal-ventral axis did not differ between $\operatorname{Trim} 9^{+/+}$and $\operatorname{Trim} 9^{-/-}$mice $(58.8 \pm 1.25 \mu \mathrm{m}$ vs $57.76 \pm 1.18 \mu \mathrm{m}$, respectively, $p=0.603)$.

Unless some form of developmental compensation occurs, defective migration of embryonic born neurons would be expected to result in hippocampal malformation regardless of the contribution of adult-born neurons. The lack of gross anatomical differences between the hippocampi of $\operatorname{Tr} i m 9^{+/+}$and $\operatorname{Tr} i m 9^{-1-}$ littermates (Figs. $1 C, D, 5 B, 6 C, 9 C$ ), therefore, are inconsistent with defective migration of embryonic-born neurons. Because we did not observe such developmentally associated deficits (Wenzel et al., 2001; Ghafari and Golalipour, 2014), this may support a specific role of TRIM9 in the migration or placement of adult-born DG neurons. Consistent with this, we labeled granule cells in the DG with CaMKII-eGFP and observed occasional mature $\mathrm{GFP}^{+}$granule cells superficial to the GCL in Trim $9^{-/-}$lit- termates (Fig. 9C, insets). This viral labeling approach also further confirmed that axons of Trim $9^{-1-}$ DG cells projected into the CA3 as expected, similar to those of adult-born Trim $9^{-1-}$ neurons at 28 DPI.

\section{Trim9 deletion does not impair motor function or affect} anxiety-like behavior

In light of the defects associated with Trim 9 deletion, but no detectable detriment to animal viability, we tested $\operatorname{Tr} i m 9^{+/+}$and Trim $9^{-1-}$ littermates using a battery of well-established behavioral assays (Pfankuch et al., 2005; Moy et al., 2008, 2009a, b; Haley et al., 2013; Olsen et al., 2013a; Raber et al., 2014; Vorhees and Williams, 2014; Urban et al., 2015) (Fig. 10), to ascertain specific neural substrates of behavior affected. Deletion of Trim 9 did not affect basic motor coordination in the rotarod test (Fig. $11 A$ ). Overall motor behavior in the open field test was not impaired, but Trim $9^{-1-}$ mice failed to habituate to the environment over the course of an hour, as measured by a lack of decrease in exploratory behavior (genotype $\times$ time interaction, $F_{(11,341)}=$ $2.11, p=0.0191)$. Trim $9^{-1-}$ mice also exhibited a distinct pattern of rearing movements during the $1 \mathrm{~h}$ test (genotype $\times$ time 

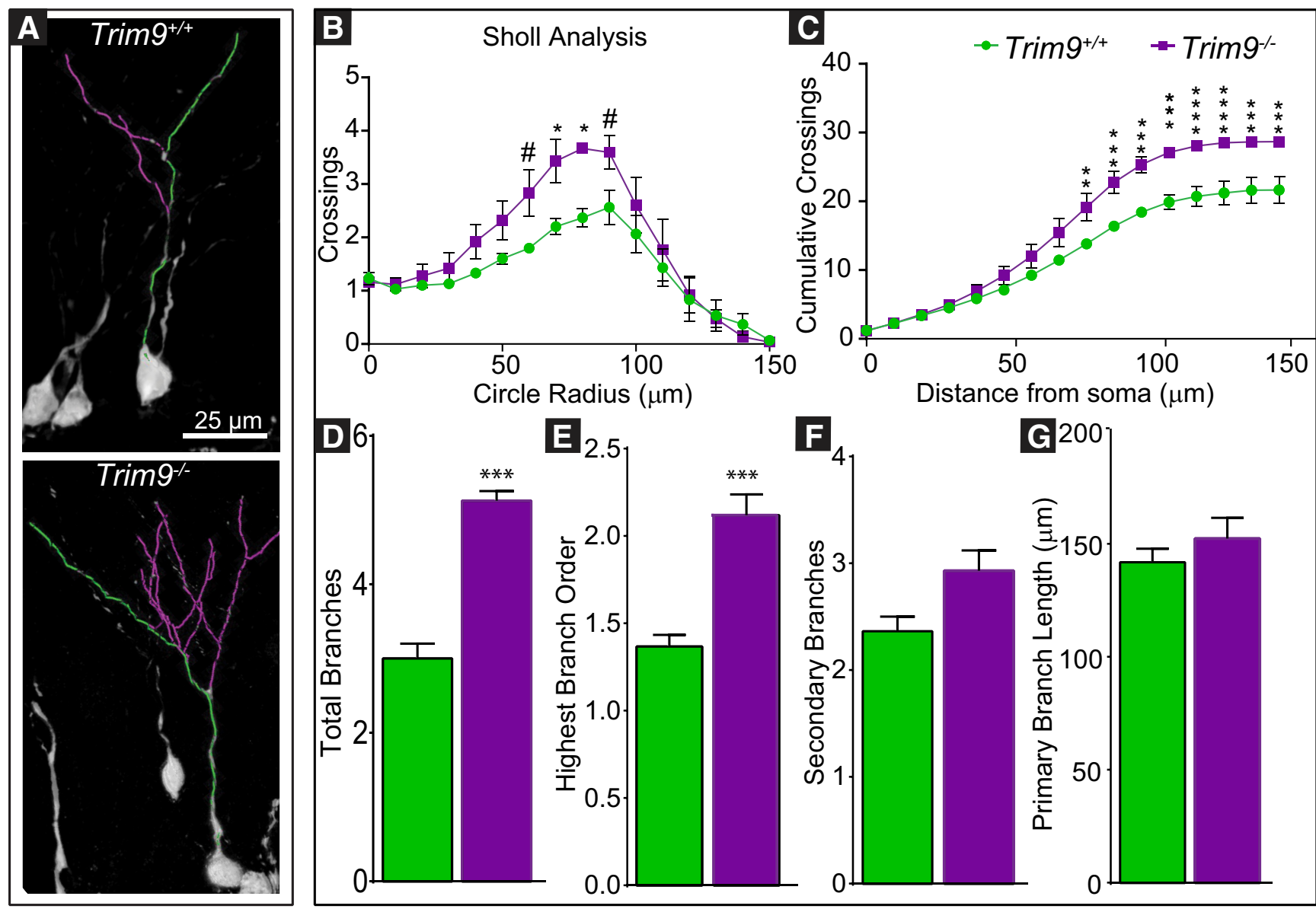

Figure 7. Deletion of Trim 9 increases dendritic arborization of adult-born hippocampal neurons from the DG in vivo. $\boldsymbol{A}, 3 \mathrm{D}$ traces overlaid on images of representative GFP ${ }^{+}$adult-born neurons $14 \mathrm{DPI}$. Green trace represents longest path from the soma (conventionally designated as the longest dendrite). Purple traces represent branches from this process. $\boldsymbol{B}$, Sholl analysis of GFP ${ }^{+}$ adult-born neurons at 14 DPI identifies increased branching in Trim $9^{-1-}$ mice, with significantly greater crossings at 70 and $80 \mu \mathrm{m}\left({ }^{*} p<0.05\right)$ and trends toward greater branching at 60 and $90 \mu \mathrm{m}$ ( ${ }^{\#} p=0.1178$ for both). C, Cumulative crossings increased with distance from the soma for both genotypes, but Trim $9^{-1-}$ mice exhibited greater crossings from $80 \mu \mathrm{m}$ and on. ${ }^{*} p<0.05$. ${ }^{* *} p<0.01{ }^{* * *} p<0.001{ }^{* * * *} p<0.0001$. Trim $9^{-1-}$ dendrites exhibit a greater number of $(\boldsymbol{D})$ total branches $(p<0.001)$ and $(\boldsymbol{E})$ increased levels of higher order branching $(p<0.01)$. $\boldsymbol{F}$, The number of secondary branches $(p=0.0699)$ and $(G)$ primary branch length did not differ between genotypes.

interaction, $\left.F_{(11,341)}=4.21, p<0.0001\right)$ (Fig. 11B). However, the two genotype groups spent similar amounts of time in the center region of the open field $\left(\right.$ Trim $9^{+/+}$, a mean sum total of $191 \pm$ $41 \mathrm{~s}, \pm$ SEM; and Trim $9^{-1-}, 227 \pm 17$ s). Because of this lack of difference in thigmotaxis, exploratory differences are not likely due to anxiety provocation of the maze, and rather to a failure to habituate, possibly consistent with impaired hippocampal function. To further assess anxiety-like behavior, we used the elevated plus maze. Mice of both genotypes exhibited a strong preference for the closed arms compared with the open arms of the elevated plus maze. There were no significant differences between the Trim $9^{+/+}$and Trim $9^{-1-}$ mice for percentage time (10 \pm 3 vs $9 \pm$ 3 ) or percentage entries ( $20 \pm 3$ vs $21 \pm 2)$ on the open arms, or for total entries during the test $(14 \pm 3,11 \pm 1)$. These data corroborate the open-field observations, suggesting that deletion of Trim9 does not affect anxiety-like behaviors, but rather exploration and habituation. To further investigate exploration behavior, we used the marble burying test. Trim $9^{-1-}$ mice buried significantly fewer marbles in $30 \mathrm{~min}(10 \pm 1.3)$ compared with Trim $9^{+/+}$littermates $(15 \pm 0.6)$, suggesting that the loss of Trim 9 alters active exploration $\left(F_{(1,31)}=8.5, p=0.0065\right)$. During the acoustic startle tests (Fig. $11 C$ ), Trim $9^{+/+}$and Trim $9^{-/-}$mice demonstrated comparable startle amplitudes, except at higher decibels during the initial testing period when Trim $9^{-1-}$ mice exhibited decreased startle responses. The acoustic startle response is preserved across many species and is considered an assay of negative affect. This process is thought to involve a complicated pathway involving the hippocampus, amygdala, and bed nucleus of the stria terminalis (Lee and Davis, 1997).

In the test for sociability (Fig. 11D), both Trim $9^{+/+}$and Trim $9^{-1-}$ mice displayed a significant preference for spending time in proximity to a stranger mouse, versus an empty cage (within-genotype repeated-measures ANOVAs, following overall significant effect of side, $\left.F_{(1,31)}=40.59, p<0.0001\right)$. In a subsequent social novelty phase, when a novel stranger was introduced (Fig. 11D), the two groups demonstrated a switch in preference to the more novel stranger 2 (effect of side, $F_{(1,31)}=$ $31.32, p<0.0001)$. However, the Trim $9^{-1-}$ mice spent less time than the Trim $9^{+/+}$mice in proximity to the first stranger mouse (main effect of genotype, $F_{(1,31)}=8.7, p=0.006$ ), suggesting that loss of Trim 9 led to a mild decrease in social preference, and perhaps an increased sensitivity to novelty. The Trim $9^{+/+}$and Trim $9^{-1-}$ mice made similar numbers of entries during the initial habituation phase (data not shown). In this test (Fig. 11D), the Trim $9^{-1-}$ mice had overall lower numbers of entries, compared with the Trim $9^{+/+}$mice, and did not make a higher number of entries into the stranger 1 side, versus the empty cage side (main effect of genotype, $F_{(1,31)}=5.69, p=0.0233$; effect of side, 

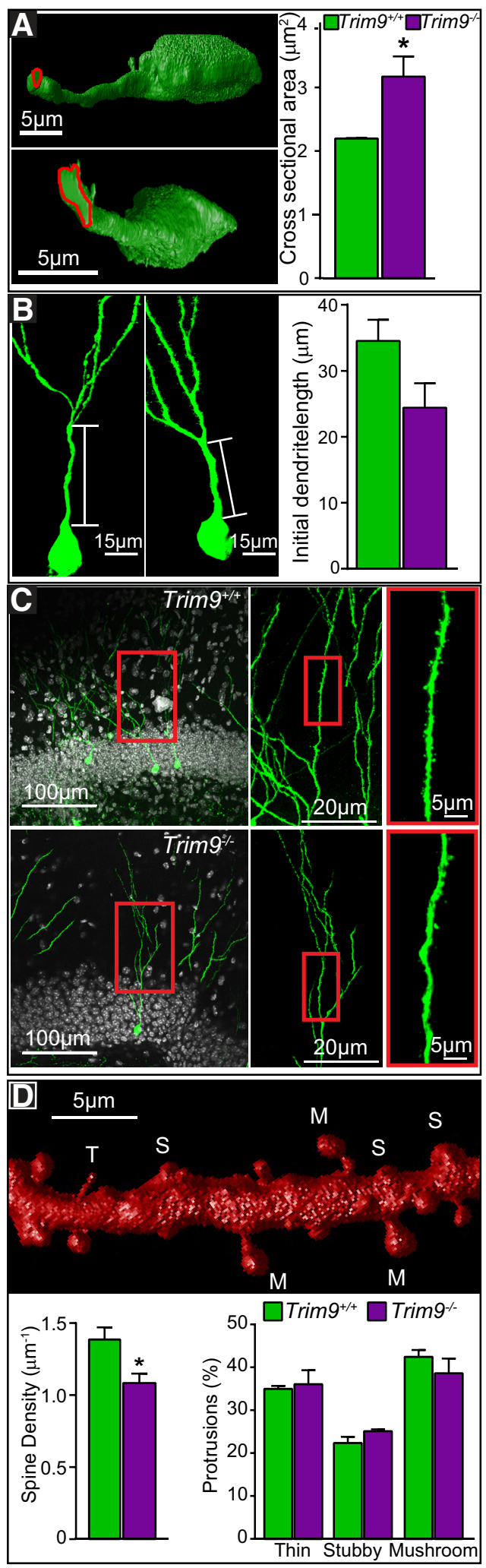

Figure 8. Deletion of Trim 9 increases the cross-sectional area of the initial dendrite segment and reduces dendritic spine density in vivo. $A, 3 D$ construction of the representative initial dendrite segments in Trim $9^{+/+}$and Trim $9^{-1-}$ mice. Red trace represents the circumference of the initial dendrite segments. Quantification of average cross-sectional areas of the primary dendrite initial segment showed that Trim $9^{-1-}$ neurons exhibited larger cross-sectional areas

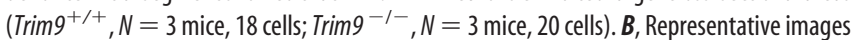
of GFP-labeled adult-born neurons show (and quantification of length of the initial dendrite segments revealed) an insignificant reduction in length of the initial dendrite segment in

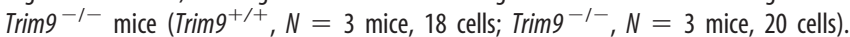

$\left.F_{(1,31)}=6.68, p=0.0147\right)$. No significant effects of genotype on number of entries were found during the subsequent social novelty phase (Fig. 11D).

\section{Trim9 deletion impairs learning and memory}

Finally, we assessed hippocampal-dependent learning and memory in the Morris Water Maze. This task requires the animal to encode spatial information into a memory and use that memory to complete an escape task. Briefly, animals must locate a platform to escape a pool of water. Initially, this platform is marked by an object that denotes the location. After learning this basic task, the marker is removed and the submerged platform must be located by relying on constant extra-maze cues that are used to establish a spatial map. Both the Trim $9^{+/+}$and $\operatorname{Trim} 9^{-/-}$mice performed proficiently in the visible platform test (Fig. 11E), suggesting that visual acuity, ability to swim, and acquisition of procedural learning were intact. In contrast, whereas Trim $9^{+/+}$ mice exhibited decreasing latency $\left(F_{(3,84)}=6.11, p=0.0008\right)$ in locating the hidden platform over subsequent trials, thus indicating spatial map formation and retrieval, Trim $9^{-1-}$ littermates failed to improve beyond their initial baseline in this task (Fig. $11 E$, interaction of trial with genotype, $F_{(1,28)}=13.8, p=0.0009$ ). Retention of the task is evaluated by removing the platform, and assaying persistence in attempting to locate the platform as measured by time spent in the quadrant of the pool where the platform was previously located. Mice that fail to demonstrate a preference for the target quadrant are considered to have poor spatial memory. Subsequently, upon removal of the hidden platform, the $\operatorname{Trim} 9^{+/+}$mice had a clear preference for crossing over the former platform location (Fig. 11E, within-genotype analysis, $\left.F_{(3,33)}=5.16, p=0.0049\right)$, whereas the $\operatorname{Tr} i m 9^{-I-}$ mice failed to demonstrate significant quadrant selectivity $\left(F_{(3,51)}=1.0, p=\right.$ $0.3984)$. Collectively, these data suggest that the genetic loss of Trim 9 severely disrupts spatial learning and memory.

\section{Discussion}

These data provide evidence for a role of the brain-enriched E3 ubiquitin ligase TRIM9 in hippocampal neuronal morphogenesis. Deletion of Trim 9 accelerates acquisition of neuronal complexity and aberrant dendritic and axonal arborization in embryonic hippocampal neurons in vitro, which is recapitulated in vivo with adult-born hippocampal neurons. These morphological defects are associated with overt spatial learning and memory deficits.

\section{TRIM9 regulates membrane expansion and actin dynamics during morphogenesis}

Neuronal morphogenesis involves dramatic remodeling of the neuronal plasma membrane, mediated by underlying dynamics of the cytoskeletal and membrane trafficking machinery and promoted by extracellular cues, such as netrin-1 (Menon and Gupton, 2016; Winkle and Gupton, 2016). TRIM9 is situated at the junction of these cellular machines where it promotes robust

C, Low-magnification views (left) of imaged 4-week-old adult-born GFP-labeled neurons and high-magnification views (right) of the dendritic segments from dentate gyrus of $\operatorname{Trim} 9^{+/+}$ and Trim $9^{-/-}$mice (left, middle, boxed segments). D, A 3D reconstruction of distinct spine types: mushroom (M), thin (T), and stubby (S). Quantification of average density of dendritic spines showing the decreased spine density in Trim $9^{-1-}$ mice. Average percentage of thin, stubby, and mushroom spines in Trim $9^{+/+}$and Trim $9^{-1-}$ mice remained unchanged $\left(\right.$ Trim $9^{+/+}, N=3$ mice, 6648 spines; Trim $9^{-1-}, N=3$ mice, 5148 spines). Student's unpaired $t$ test. Error bars indicate SEM. ${ }^{*} p<0.05$. 

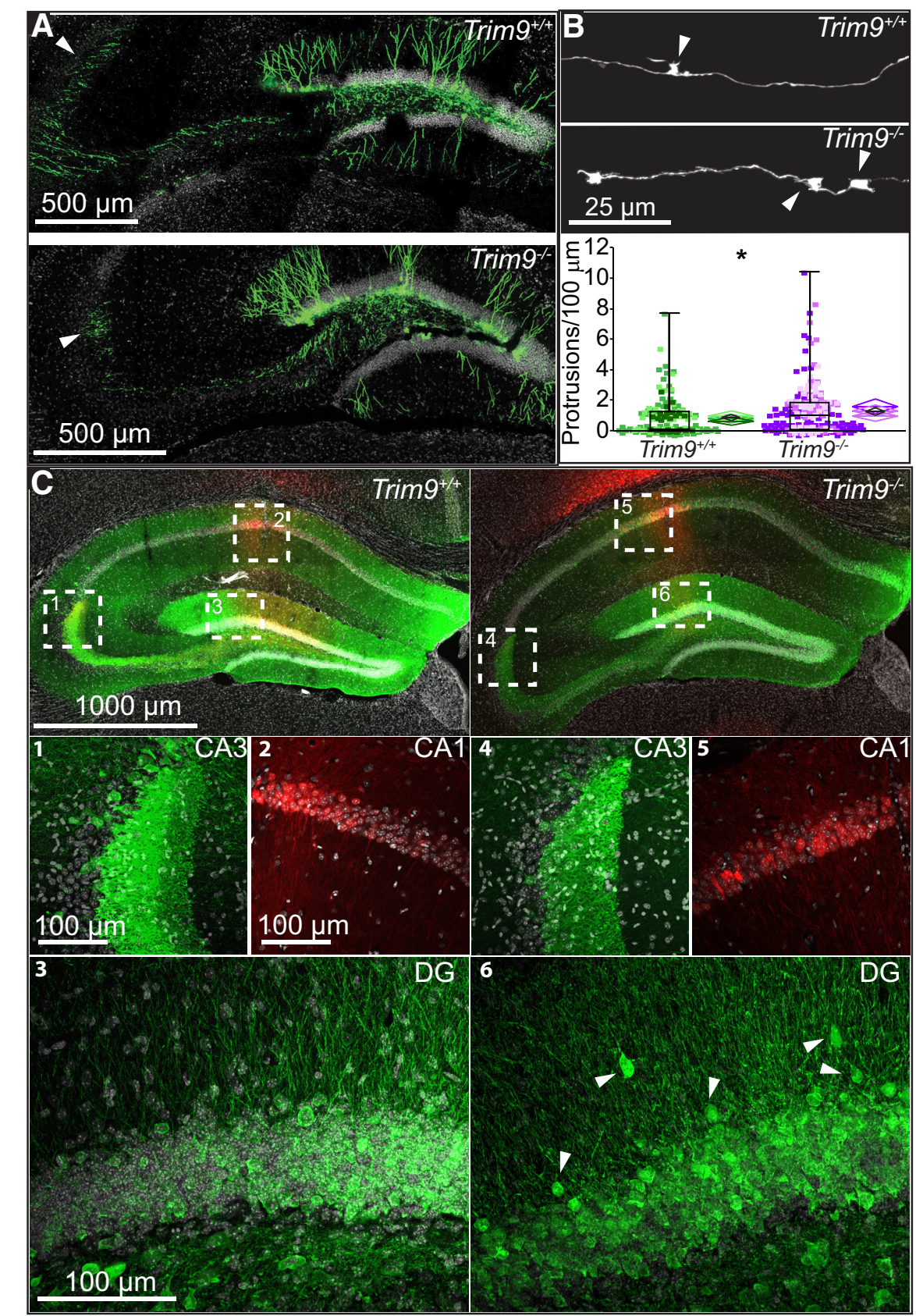

Figure 9. Disruptions in axonal targeting of DG neurons or placement of CA1 neurons are not detected in the absence of Trim 9 . $\boldsymbol{A}$, At $28 \mathrm{DPI}$, adult-born Trim $9^{+/+}$and Trim $9^{-/-}$mice extended axons to CA3 (arrowheads). $\boldsymbol{B}$, Representative renderings from $3 \mathrm{D}$ traces of GFP ${ }^{+}$newborn granule cell axons targeting $\mathrm{CA} 3$, demonstrating axonal protrusions (arrowheads) and quantification of the number of protrusions $/ 100 \mu \mathrm{m}$ length $\left(\right.$ Trim $9^{+/+}, N=3$ mice, 153 axonal segments; Trim $9^{-1-}, N=3$ mice, 207 axonal segments). ${ }^{*} p<0.05$. Data from individual mice are represented in a distinct color. C, Gross adult hippocampal architecture is largely preserved in Trim $9^{-1-}$ mice. CaMKII-eGFP-labeled granule cells project to CA3 (C1, C4). Somatic mistargeting is not detected in CaMKII-mCherry-labeled CA1 pyramidal cells $(\mathbf{C 2}, \mathbf{C 5})$. Occasional mature granule cells were observed in the inner molecular cell layer in Trim $9^{-/-}$mice.

changes in morphology. First, TRIM9 directly binds the SNARE complex component SNAP25 (Li et al., 2001). Through this interaction, TRIM9 blocks exocytic SNARE activity and thus the plasma membrane expansion necessary for axon branching (Winkle et al., 2014). TRIM9 also directly interacts with the netrin receptor DCC, and netrin stimulation inhibits the TRIM9 interaction with SNAP25, promoting exocytic and axon branching responses (Winkle et al., 2014). Second, TRIM9-mediated ubiquitination of the actin polymerase VASP decreases the sta-

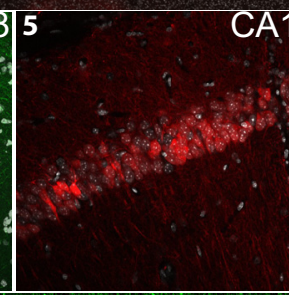

bility of axonal growth cone filopodia (Menon et al., 2015). In the absence of Trim9, growth cones exhibit higher densities of stable filopodia. Filopodia are considered axon guidance sensors, and correspondingly deletion of Trim 9 is associated with axon guidance defects in vitro and in vivo. These molecular targets of TRIM9 are likely involved in hippocampal neuron morphogenesis as well. Indeed, SNAP25, VASP, and TRIM9 are present within dendrites (Jordan et al., 2004; Lin et al., 2010; Menna et al., 2011) and may contribute to the alterations in dendritic swelling, branching density, and spine density observed here. The increase in axonal protrusions present in vivo in $\operatorname{Trim} 9^{-1-}$ animals may indicate impaired cytoskeletal function, a hypothesis consistent with the involvement of TRIM9mediated regulation of VASP (Menon et al., 2015). The hippocampal presence of the TRIM9 isoform lacking the DCCbinding SPRY domain (Winkle et al., 2014) is consistent with additional netrinindependent functions for TRIM9.

\section{A possible role for netrin and TRIM9 in adult neurogenesis}

The interaction between TRIM9 and the netrin receptor DCC is conserved in invertebrate orthologs, where it modulates cellular response to netrin, including axon guidance, branching, and cell migration (Hao et al., 2010; Morikawa et al., 2011; Winkle et al., 2014). Loss of the Trim 9 ortholog in Caenorhabditis elegans is associated with a failure in migration of the anchor cell toward an asymmetric netrin source (Morf et al., 2013; Wang et al., 2014). Because netrin- 1 is absent from the hilus (Yang et al., 2008), it is intriguing to hypothesize that $\operatorname{Trim} 9^{-1-}$ adult-born DG neurons aberrantly migrate due to a loss of sensitivity to normal netrin cues located outside of the hilus. Migration of adult-born neurons from the DG to the hilus occurs in epileptic conditions, and Reelin, or ApoER2/VLDR2 impairments (Hack et al., 2002). Notably, intense epileptic conditions induce expression of the guidance cues netrin- 1 and semaphorin 3A in the hilar region (Yang et al., 2008). Similar to loss of Trim9, disruption of reelin, the VLDLR, and ApoE systems also produce impairments in hippocampal-dependent tasks (Olsen et al., 2012; Johnson et al., 2014).

Neogenin, which is closely related to DCC, is predicted to interact with TRIM9 (Meyerhardt et al., 1997; Morikawa et al., 2011). Netrin and neogenin are involved in dendritic selfavoidance in Drosophila melanogaster (Smith et al., 2012), which may be consistent with altered dendritic arborization observed in hippocampal neurons following netrin stimulation or $\operatorname{Trim} 9 \mathrm{de}-$ 
letion. Netrin-1 and neogenin are also expressed in the neurogenic niches of the subventricular zone and rostral migratory stream in the mammalian forebrain, which contain newly born, migrating neural precursors (Bradford et al., 2010). Neogenin directly regulates the migration of adult-born neurons to the olfactory bulb (O'Leary et al., 2015). Similarly, closely related netrin-5 is expressed in the DG, rostral migratory stream, and subventricular zones (Yamagishi et al., 2015), and based on homology to netrin-1, is likely recognized by DCC and neogenin. The presence of different netrin proteins and netrin receptors in neurogenic niches and migratory streams (Bradford et al., 2010) suggests that they may play a role in the generation, migration, or morphogenesis of newborn neurons. Our findings of disrupted morphogenesis and migration of Trim $9^{-1-}$ adult-born DG neurons are consistent with this. Investigation of netrin-1 function specifically in adult neurogenesis has been hindered, as mice carrying a gene trap in Ntn1 die perinatally (Serafini et al., 1996). The recent development of conditional alleles for the gene encoding netrin (Ntn1) (Bin et al., 2015; Yung et al., 2015) makes exploration of this neurogenic role possible.

\section{The role of TRIM9 in adult neurogenesis and hippocampus-dependent tasks}

Proper function of the hippocampus is crucial for high-order cognition, such as spatial learning and memory, which is often disrupted in neurological disorders (Boyer et al., 2007). Here we illustrate that both Trim $9^{+/+}$and $\operatorname{Tr} i m 9^{-/-}$mice acquire a basic procedural task, specifically locating a visible escape platform in the initial phase of the water maze. However, only Trim $9^{+/+}$ animals learn, and subsequently recall, the portion of the task that requires generating a spatial map to locate the platform. Trim $9^{-1-}$ mice never acquire this behavior, suggesting a selective hippocampal-dependent learning deficit. Overall, the overt deficits in spatial learning and memory and only subtle deficits in other behavioral tasks indicate that deletion of Trim9 led to specific deficits in hippocampal-dependent learning, without severe effects on other functions.

Hippocampal neurogenesis is implicated in the acquisition of spatial reference memory during the learning phase of the hidden water maze procedure (Xavier et al., 1999; Dupret et al., 2008). New neurons in the DG are more selectively active during spatial learning tasks, such as the water maze, and maturing adult-born neurons actively contribute to learning and memory processes (Deng et al., 2009; Snyder et al., 2009). Morphological maturation of these cells is dependent on both internal processes and feedback from the local environment (Song et al., 2015).

The deficits we found in morphology and integration of adult-born neurons in the absence of Trim 9 may therefore contribute to the learning deficits exhibited by these mice. $\operatorname{Trim} 9^{-1-}$ adult-born neurons displayed a higher incidence of somal mislocalization and decreased synapse density but still appeared to incorporate into the local circuitry. These changes could affect their synaptic partners, with detrimental consequences for hippocampal-dependent behavior. In addition, a
Week 2 \begin{tabular}{|l|l|} 
Rotarod test \\
Reek 3
\end{tabular} Social Approach Week 5 Marble Bury Assay/ Acoustic Startle Test 1 Week 6 Buried Food Olfaction Week 7-9 Morris Water Maze Week 10 Acoustic Startle Test

gure 10. The time frame and order in which behavioral tests were administered.

number of dendritic morphology changes observed in Trim $9^{-1-}$ neurons could alter their functional incorporation into such circuitry. The hyperarborization of Trim $9^{-1-}$ neurons creates an extended receptive field for inputs, which could disrupt the specificity of incoming excitatory stimuli onto granule cells. Reduced dendritic spine density would further alter the organization of excitatory inputs and reduce the number of contacts received by each neuron (Spruston, 2008; Stone et al., 2011). As granule cells are selectively recruited by incoming stimuli, which facilitate learning and memory, sensory integration, and pattern separation, this could produce significant defects in any of these cognitive processes. Furthermore, newborn neurons are preferentially recruited in these tasks (Kee et al., 2007), suggesting that the persistent deficits observed in Trim $9^{-1-}$ mice could be especially damaging to learning and memory. The increased diameter of the initial dendritic process of Trim $9^{-1-}$ immature neurons may alter passive-cable properties and reduce membrane resistance, leading to reduced excitability, as suggested (Tran-Van-Minh et al., 2015). These morphology alterations could disrupt appropriate synaptic input and integration, thus impairing the hippocampal network. Such abnormalities in dendrites and dendritic spines have been observed in neuropathological conditions (Kaufmann and Moser, 2000; Gao et al., 2011; Kirkwood et al., 2013) and may contribute to the behavioral deficits observed in Trim $9^{-1-}$ mice.

The TRIM family of E3 ligases are implicated in multiple cellular processes, and mutations in TRIM genes occur in several human diseases (Hatakeyama, 2011; Napolitano and Meroni, 2012; Alloush and Weisleder, 2013; Mandell et al., 2014; Rajsbaum et al., 2014). Our findings identify a novel role for TRIM9 in the developing adult hippocampus, in which genetic loss of Trim9 exaggerates arbor complexity and is associated with severe deficits in spatial learning and memory. Recent genome-wide association study data identified topranked SNPs in human TRIM9 in a small cohort of patients with atypical psychosis (Kanazawa et al., 2013). Schizoaffective disorder, also known as atypical psychosis or brief psychotic disorder, and similar mental illnesses, such as bipolar disorder and schizophrenia, are often characterized by disorganized thoughts, impairments of spatial cognition and intellectual performance, and the misidentification of places and people. This possible connection between TRIM9 and hippocampal dysfunction is intriguing. 

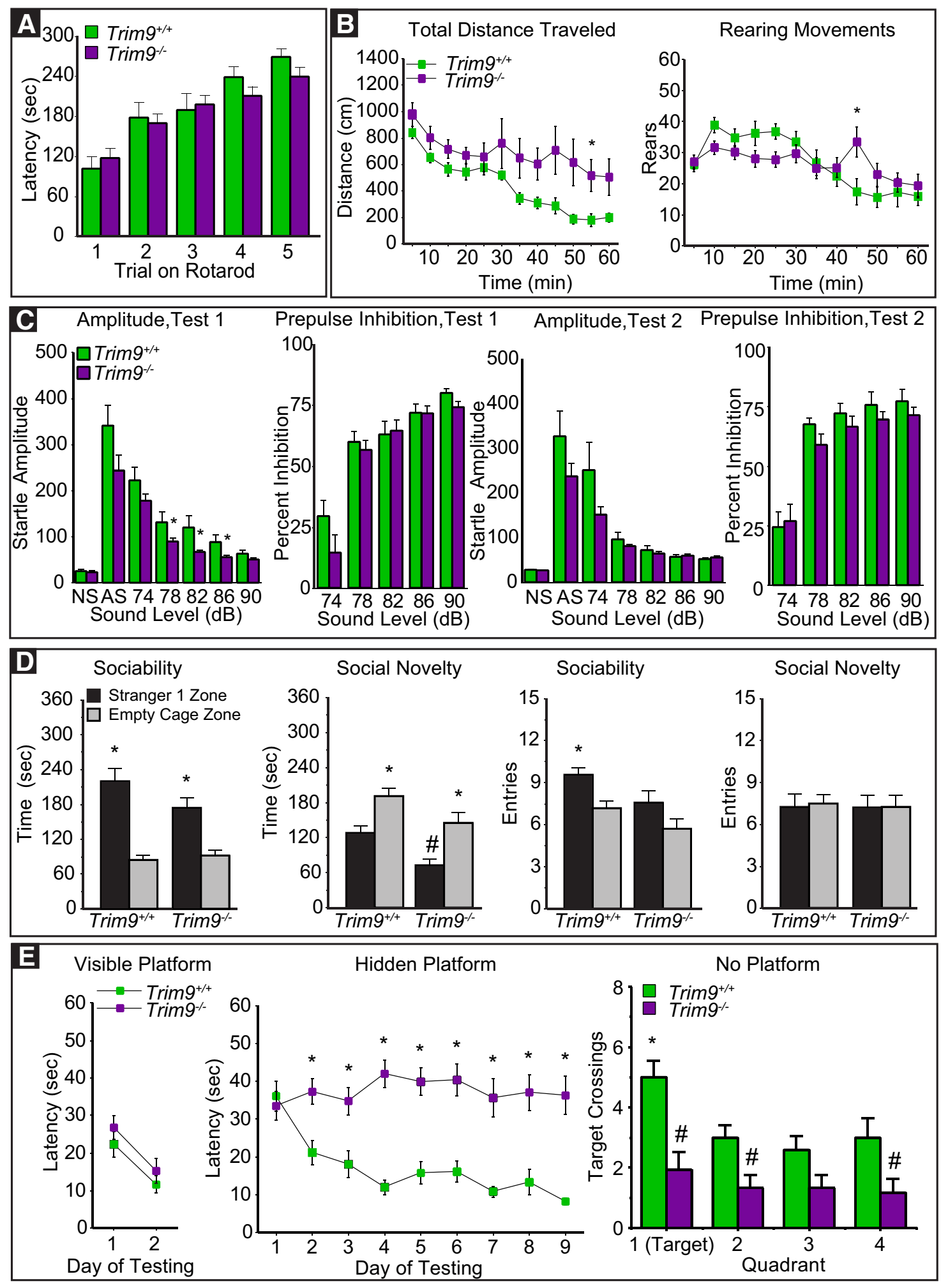

Figure 11. Genetic loss of Trim 9 is associated with hippocampal-dependent defects in spatial learning and memory. $\boldsymbol{A}$, Results of rotarod test for movement disorders. $\boldsymbol{B}$, Results of open field test showing hyperactivity in Trim $9^{-1-}$ animals. C, Results of the auditory startle test showing decreased startle amplitude during the initial testing of $\operatorname{Trim} 9^{-/-}$animals. D, Performance in the sociability and social novelty task. $\boldsymbol{E}$, Results of the Morris Water Maze test for learning and memory showing that Trim $9^{-1-}$ animals perform as expected when the platform is visible but display marked defects in ability to find the hidden platform and in crossing of the target quadrant in the No Platform condition. ${ }^{*} p<0.05$ comparison with Trim $9^{+/+}\left(\boldsymbol{B}-\boldsymbol{E}\right.$, Hidden Platform). ${ }^{*} p<0.05$, within-genotype comparison ( $\boldsymbol{D}, \boldsymbol{E}$, No Platform). ${ }^{\#} p<0.05$, comparison with Trim $9^{+/+}$(D, $\boldsymbol{E}$, No Platform).

Although E3 ubiquitin ligases often have multiple substrates, only a single substrate for TRIM9 has been identified thus far (Menon et al., 2015). Further investigation of the molecular function of TRIM9 is warranted to identify its substrates and modes of action. As E3 ubiquitin ligases are potentially druggable targets (Cohen and Tcherpakov, 2010) and newborn granule cells may be therapeutically tractable, TRIM9 may represent a putative entry point for future therapeutic intervention. 


\section{References}

Alloush J, Weisleder N (2013) TRIM proteins in therapeutic membrane repair of muscular dystrophy. JAMA Neurol 70:928-931. CrossRef Medline

Barallobre MJ, Del Río JA, Alcántara S, Borrell V, Aguado F, Ruiz M, Carmona MA, Martín M, Fabre M, Yuste R, Tessier-Lavigne M, Soriano E (2000) Aberrant development of hippocampal circuits and altered neural activity in netrin 1-deficient mice. Development 127: 4797-4810. Medline

Berti C, Messali S, Ballabio A, Reymond A, Meroni G (2002) TRIM9 is specifically expressed in the embryonic and adult nervous system. Mech Dev 113:159-162. CrossRef Medline

Bin JM, Han D, Lai Wing Sun K, Croteau LP, Dumontier E, Cloutier JF, Kania A, Kennedy TE (2015) Complete loss of netrin-1 results in embryonic lethality and severe axon guidance defects without increased neural cell death. Cell Rep 12:1099-1106. CrossRef Medline

Boyer P, Phillips JL, Rousseau FL, Ilivitsky S (2007) Hippocampal abnormalities and memory deficits: New evidence of a strong pathophysiological link in schizophrenia. Brain Res Rev 54:92-112.

Bradford D, Faull RL, Curtis MA, Cooper HM (2010) Characterization of the netrin/RGMa receptor neogenin in neurogenic regions of the mouse and human adult forebrain. J Comp Neurol 518:3237-3253. CrossRef Medline

Bradke F, Dotti CG (2000) Establishment of neuronal polarity: lessons from cultured hippocampal neurons. Curr Opin Neurobiol 10:574-581. CrossRef Medline

Chatzi C, Zhang G, Shen R, Westbrook GL, Goodman RH (2016) Transcriptional profiling of newly generated dentate granule cells using TUtagging reveals pattern shifts in gene expression during circuit integration. 2016 Mar 7;3(1). pii: ENEURO.0024-16.2016. doi: 10.1523/ ENEURO.0024-16.2016

Christian KM, Song H, Ming GL (2014) Functions and dysfunctions of adult hippocampal neurogenesis. Annu Rev Neurosci 37:243-262. CrossRef Medline

Cohen P, Tcherpakov M (2010) Will the ubiquitin system furnish as many drug targets as protein kinases? Cell 143:686-693. CrossRef Medline

Deng W, Saxe MD, Gallina IS, Gage FH (2009) Adult-born hippocampal dentate granule cells undergoing maturation modulate learning and memory in the brain. J Neurosci 29:13532-13542. CrossRef Medline

Deng W, Aimone JB, Gage FH (2010) New neurons and new memories: how does adult hippocampal neurogenesis affect learning and memory? Nat Rev Neurosci 11:339-350. CrossRef Medline

Dent EW, Gupton SL, Gertler FB (2011) The growth cone cytoskeleton in axon outgrowth and guidance. Cold Spring Harb Perspect Biol 3:a001800. CrossRef Medline

Dotti CG, Sullivan CA, Banker GA (1988) The establishment of polarity by hippocampal neurons in culture. J Neurosci 8:1454-1468. Medline

Dupret D, Revest JM, Koehl M, Ichas F, De Giorgi F, Costet P, Abrous DN, Piazza PV (2008) Spatial relational memory requires hippocampal adult neurogenesis. PLoS One 3:e1959. CrossRef Medline

Fazeli A, Dickinson SL, Hermiston ML, Tighe RV, Steen RG, Small CG, Stoeckli ET, Keino-Masu K, Masu M, Rayburn H, Simons J, Bronson RT, Gordon JI, Tessier-Lavigne M, Weinberg RA (1997) Phenotype of mice lacking functional deleted in colorectal cancer. Nature 386:796-804. CrossRef Medline

Feng G, Mellor RH, Bernstein M, Keller-Peck C, Nguyen QT, Wallace M, Nerbonne JM, Lichtman JW, Sanes JR (2000) Imaging neuronal subsets in transgenic mice expressing multiple spectral variants of GFP. Neuron 28:41-51. CrossRef Medline

Gao X, Deng P, Xu ZC, Chen J (2011) Moderate traumatic brain injury causes acute dendritic and synaptic degeneration in the hippocampal dentate gyrus. PLoS One 6:e24566. CrossRef Medline

Gaykema RP, van der Kuil J, Hersh LB, Luiten PG (1991) Patterns of direct projections from the hippocampus to the medial septum-diagonal band complex: anterograde tracing with phaseolus vulgaris leucoagglutinin combined with immunohistochemistry of choline acetyltransferase. Neuroscience 43:349-360. CrossRef Medline

Ghafari S, Golalipour MJ (2014) Prenatal morphine exposure reduces pyramidal neurons in CA1, CA2 and CA3 subfields of mice hippocampus. Iranian J Basic Med Sci 17:155-161.
Goebbels S, Bormuth I, Bode U, Hermanson O, Schwab MH, Nave KA (2006) Genetic targeting of principal neurons in neocortex and hippocampus of NEX-Cre mice. Genesis 44:611-621. CrossRef Medline

Gong S, Zheng C, Doughty ML, Losos K, Didkovsky N, Schambra UB, Nowak NJ, Joyner A, Leblanc G, Hatten ME, Heintz N (2003) A gene expression atlas of the central nervous system based on bacterial artificial chromosomes. Nature 425:917-925. CrossRef Medline

Gupton SL, Gertler FB (2010) Integrin signaling switches the cytoskeletal and exocytic machinery that drives neuritogenesis. Dev Cell 18:725-736. CrossRef Medline

Hack I, Bancila M, Loulier K, Carroll P, Cremer H (2002) Reelin is a detachment signal in tangential chain-migration during postnatal neurogenesis. Nat Neurosci 5:939-945. CrossRef Medline

Haley GE, Yeiser L, Olsen RHJ, Davis MJ, Johnson LA, Raber J (2013) Early effects of whole-body (56)Fe irradiation on hippocampal function in C57BL/6J mice. Rad Res 179:590-596.

Hao JC, Adler CE, Mebane L, Gertler FB, Bargmann CI, Tessier-Lavigne M (2010) The tripartite motif protein MADD-2 functions with the receptor UNC-40 (DCC) in netrin-mediated axon attraction and branching. Dev Cell 18:950-960. CrossRef Medline

Hatakeyama S (2011) TRIM proteins and cancer. Nat Rev Cancer 11: 792-804. CrossRef Medline

Higginbotham H, Eom TY, Mariani LE, Bachleda A, Hirt J, Gukassyan V, Cusack CL, Lai C, Caspary T, Anton ES (2012) Arl13b in primary cilia regulates the migration and placement of interneurons in the developing cerebral cortex. Dev Cell 23:925-938. CrossRef Medline

Johnson LA, Olsen RH, Merkens LS, DeBarber A, Steiner RD, Sullivan PM, Maeda N, Raber J (2014) Apolipoprotein E-low density lipoprotein receptor interaction affects spatial memory retention and brain ApoE levels in an isoform-dependent manner. Neurobiol Dis 64:150-162. CrossRef Medline

Jordan BA, Fernholz BD, Boussac M, Xu C, Grigorean G, Ziff EB, Neubert TA (2004) Identification and verification of novel rodent postsynaptic density proteins. Mol Cell Proteomics 3:857-871. CrossRef Medline

Kanazawa T, Ikeda M, Glatt SJ, Tsutsumi A, Kikuyama H, Kawamura Y, Nishida N, Miyagawa T, Hashimoto R, Takeda M, Sasaki T, Tokunaga K, Koh J, Iwata N, Yoneda H (2013) Genome-wide association study of atypical psychosis. Am J Med Genet 162:679-686. CrossRef Medline

Kaufmann WE, Moser HW (2000) Dendritic anomalies in disorders associated with mental retardation. Cereb Cortex 10:981-991. CrossRef Medline

Kee N, Teixeira CM, Wang AH, Frankland PW (2007) Preferential incorporation of adult-generated granule cells into spatial memory networks in the dentate gyrus. Nat Neurosci 10:355-362. CrossRef Medline

Kim TY, Siesser PF, Rossman KL, Goldfarb D, Mackinnon K, Yan F, Yi X, MacCoss MJ, Moon RT, Der CJ, Major MB (2015) Substrate trapping proteomics reveals targets of the $\beta \operatorname{TrCP} 2 / \mathrm{FBXW} 11$ ubiquitin ligase. Mol Cell Biol 35:167-181.

Kirkwood CM, Ciuchta J, Ikonomovic MD, Fish KN, Abrahamson EE, Murray PS, Klunk WE, Sweet RA (2013) Dendritic spine density, morphology, and fibrillar actin content surrounding amyloid-B plaques in a mouse model of amyloid-B deposition. J Neuropathol Exp Neurol 72: 791-800. CrossRef Medline

Lebrand C, Dent EW, Strasser GA, Lanier LM, Krause M, Svitkina TM, Borisy GG, Gertler FB (2004) Critical role of Ena/VASP proteins for filopodia formation in neurons and in function downstream of netrin-1. Neuron 42:37-49. CrossRef Medline

Lee Y, Davis M (1997)) Role of the hippocampus, the bed nucleus of the stria terminalis, and the amygdala in the excitatory effect of corticotropin-releasing hormone on the acoustic startle reflex. J Neurosci 17:6434-6446. Medline

Li Y, Chin LS, Weigel C, Li L (2001) Spring, a novel RING finger protein that regulates synaptic vesicle exocytosis. J Biol Chem 276:40824-40833. CrossRef Medline

Lin WH, Nebhan CA, Anderson BR, Webb DJ (2010) Vasodilatorstimulated phosphoprotein (VASP) induces actin assembly in dendritic spines to promote their development and potentiate synaptic strength. J Biol Chem 285:36010-36020. CrossRef Medline

Mandell MA, Jain A, Arko-Mensah J, Chauhan S, Kimura T, Dinkins C, Silvestri G, Münch J, Kirchhoff F, Simonsen A, Wei Y, Levine B, Johansen T, Deretic V (2014) TRIM proteins regulate autophagy and can target 
autophagic substrates by direct recognition. Dev Cell 30:394-409. CrossRef Medline

Menna E, Fossati G, Scita G, Matteoli M (2011) From filopodia to synapses: the role of actin-capping and anti-capping proteins. Eur J Neurosci 34: 1655-1662. CrossRef Medline

Menon S, Boyer NP, Winkle CC, McClain LM, Hanlin CC, Pandey D, Rothenfußer S, Taylor AM, Gupton SL (2015) The E3 Ubiquitin ligase TRIM9 is a filopodia off switch required for netrin-dependent axon guidance. Dev Cell 35:698-712.

Menon S and Gupton SL (2016) The Building Blocks of a Functioning Brain: Cytoskeletal Dynamics in Neuronal Development. International Review of Cell and Molecular Biology. Elsevier Academic Press. Vol. 322. Chapter 3:183-246.

Meyerhardt JA, Look AT, Bigner SH, Fearon ER (1997) Identification and characterization of neogenin, a DCC-related gene. Oncogene 14:1129-1136. CrossRef Medline

Ming GL, Song H (2011) Adult neurogenesis in the mammalian brain: significant answers and significant questions. Neuron 70:687-702. CrossRef Medline

Morf MK, Rimann I, Alexander M, Roy P, Hajnal A (2013) The Caenorhabditis elegans homolog of the Opitz syndrome gene, Madd-2/Mid1, regulates anchor cell invasion during vulval development. Dev Biol 374: 108-114. CrossRef Medline

Morikawa RK, Kanamori T, Yasunaga K, Emoto K (2011) Different levels of the tripartite motif protein, anomalies in sensory axon patterning (ASAP), regulate distinct axonal projections of Drosophila sensory neurons. Proc Natl Acad Sci U S A 108:19389-19394. CrossRef Medline

Moy SS, Nadler JJ, Young NB, Nonneman RJ, Segall SK, Andrade GM, Crawley JN, Magnuson TR (2008) Social approach and repetitive behavior in eleven inbred mouse strains. Behavioural Brain Research 191:118-129.

Moy SS, Nadler JJ, Young NB, Nonneman RJ, Grossman AW, Murphy DL, D'Ercole AJ, Crawley JN, Magnuson TR, Lauder JM (2009a) Social approach in genetically engineered mouse lines relevant to autism. Genes, Brain and Behavior 8:129-142.

Moy SS, Nonneman RJ, Young NB, Demyanenko GP, Maness PF (2009b) Impaired sociability and cognitive function in Nrcam-null mice. Behavioural Brain Research 205:123-131.

Napolitano LM, Meroni G (2012) TRIM family: pleiotropy and diversification through homomultimer and heteromultimer formation. IUBMB Life 64:64-71. CrossRef Medline

O'Leary CJ, Bradford D, Chen M, White A, Blackmore DG, Cooper HM (2015) The Netrin/RGM receptor, Neogenin, controls adult neurogenesis by promoting neuroblast migration and cell cycle exit. Stem Cells 33:503-514. CrossRef Medline

Olsen RHJ, Agam M, Davis MJ, Raber J (2012) ApoE isoform-dependent deficits in extinction of contextual fear conditioning. Genes, Brain Behavior 11:806-812. CrossRef Medline

Olsen RHJ, Allen CN, Derkach VA, Phillips TJ, Belknap JK, Raber J (2013a) Impaired memory and reduced sensitivity to the circadian period lengthening effects of methamphetamine in mice selected for high methamphetamine consumption. Behavioural Brain Res 256:197-204.

Olsen RHJ, Johnson LA, Zuloaga DG, Limoli CL, Raber J (2013b) Enhanced hippocampus-dependent memory and reduced anxiety in mice overexpressing human catalase in mitochondria. J Neurochem 125:303-313.

Penzes P, Cahill ME, Jones KA, VanLeeuwen JE, Woolfrey KM (2011) Dendritic spine pathology in neuropsychiatric disorders. Nat Neurosci 14: 285-293. CrossRef Medline

Pfankuch T, Rizk A, Olsen R, Poage C, Raber J (2005) Role of circulating androgen levels in effects of apoE4 on cognitive function. Brain Res 1053: $88-96$.

Pfenninger KH (2009) Plasma membrane expansion: a neuron's herculean task. Nat Rev Neurosci 10:251-261. CrossRef Medline

Pun RY, Rolle IJ, Lasarge CL, Hosford BE, Rosen JM, Uhl JD, Schmeltzer SN, Faulkner C, Bronson SL, Murphy BL, Richards DA, Holland KD, Danzer SC (2012) Excessive activation of mTOR in postnatally-generated granule cells is sufficient to cause epilepsy. Neuron 75:1022-1034. CrossRef Medline

Raber J, Olsen RHJ, Su W, Foster S, Xing R, Acevedo SF, Sherman LS (2014) $\mathrm{CD} 44$ is required for spatial memory retention and sensorimotor functions. Behavioural Brain Res 275:146-149.
Rajsbaum R, García-Sastre A, Versteeg GA (2014) TRIMmunity: the roles of the TRIM E3-ubiquitin ligase family in innate antiviral immunity. J Mol Biol 426:1265-1284. CrossRef Medline

Rodriguez A, Ehlenberger DB, Dickstein DL, Hof PR, Wearne SL (2008) Automated three-dimensional detection and shape classification of dendritic spines from fluorescence microscopy images. PLoS One 3:e1997. CrossRef Medline

Schindelin J, Arganda-Carreras I, Frise E, Kaynig V, Longair M, Pietzsch T, Preibisch S, Rueden C, Saalfeld S, Schmid B, Tinevez JY, White DJ, Hartenstein V, Eliceiri K, Tomancak P, Cardona A (2012) Fiji: an opensource platform for biological-image analysis. Nat Methods 9:676-682. CrossRef Medline

Serafini T, Colamarino SA, Leonardo ED, Wang H, Beddington R, Skarnes WC, Tessier-Lavigne M (1996) Netrin-1 is required for commissural axon guidance in the developing vertebrate nervous system. Cell 87: 1001-1014. CrossRef Medline

Serafini T, Kennedy TE, Galko MJ, Mirzayan C, Jessell TM, Tessier-Lavigne M (1994) The netrins define a family of axon outgrowth-promoting proteins homologous to C. elegans UNC-6. Cell 78:409-424. CrossRef Medline

Smith CJ, Watson JD, Vanhoven MK, Colón-Ramos DA, Miller DM 3rd (2012) Netrin (UNC-6) mediates dendritic self-avoidance. Nat Neurosci 15:731-737. CrossRef Medline

Snyder JS, Radik R, Wojtowicz JM, Cameron HA (2009) Anatomical gradients of adult neurogenesis and activity: young neurons in the ventral dentate gyrus are activated by water maze training. Hippocampus 19: 360-370. CrossRef Medline

Song J, Sun J, Moss J, Wen Z, Sun GJ, Hsu D, Zhong C, Davoudi H, Christian KM, Toni N, Ming G-L, Song H (2013) Parvalbumin interneurons mediate neuronal circuitry-neurogenesis coupling in the adult hippocampus. Nat Neurosci 16:1728-1730.

Song J, Olsen RH, Sun J, Ming G, Song H (2015) Neuronal circuitry mechanisms regulating adult mammalian neurogenesis. Cold Spring Harb Perspect Biol. 289-308. 10.1101/cshperspect.a018937.

Spillane M, Ketschek A, Jones SL, Korobova F, Marsick B, Lanier L, Svitkina T, Gallo G (2011) The actin nucleating Arp $2 / 3$ complex contributes to the formation of axonal filopodia and branches through the regulation of actin patch precursors to filopodia. Dev Neurobiol 71:747-758. CrossRef Medline

Spruston N (2008) Pyramidal neurons: dendritic structure and synaptic integration. Nat Rev Neurosci 9:206-221. CrossRef Medline

Stone SSD, Teixeira CM, Devito LM, Zaslavsky K, Josselyn SA, Lozano AM, Frankland PW (2011) Stimulation of entorhinal cortex promotes adult neurogenesis and facilitates spatial memory. J Neurosci 31:13469-13484

Tanji K, Kamitani T, Mori F, Kakita A, Takahashi H, Wakabayashi K (2010) TRIM9, a novel brain-specific E3 ubiquitin ligase, is repressed in the brain of Parkinson's disease and dementia with Lewy bodies. Neurobiol Dis 38:210-218. CrossRef Medline

Tran-Van-Minh A, Cazé RD, Abrahamsson T, Cathala L, Gutkin BS, DiGregorio DA (2015) Contribution of sublinear and supralinear dendritic integration to neuronal computations. Front Cell Neurosci 9:67. CrossRef Medline

Urban DJ, Zhu H, Marcinkiewcz CA, Michaelides M, Oshibuchi H, Rhea D, Aryal DK, Farrell MS, Lowery-Gionta E, Olsen RHJ, Wetsel WC, Kash TL, Hurd YL, Tecott LH, Roth BL (2016) Elucidation of the Behavioral Program and Neuronal Network Encoded by Dorsal Raphe Serotonergic Neurons. Neuropsychopharmacology 41:1404-1415.

Viesselmann C, Ballweg J, Lumbard D, Dent EW (2011) Nucleofection and primary culture of embryonic mouse hippocampal and cortical neurons. J Vis Exp 47:e23733. CrossRef Medline

Vorhees CV, Williams MT (2014) Value of water mazes for assessing spatial and egocentric learning and memory in rodent basic research and regulatory studies. Neurotoxicol Teratol 45:75-90.

Wang Z, Linden LM, Naegeli KM, Ziel JW, Chi Q, Hagedorn EJ, Savage NS, Sherwood DR (2014) UNC-6 (Netrin) stabilizes oscillatory clustering of the UNC-40 (DCC) receptor to orient polarity. J Cell Biol 206:619-633. CrossRef Medline

Wenzel HJ, Robbins CA, Tsai LH, Schwartzkroin PA (2001) Abnormal morphological and functional organization of the hippocampus in a 35 mutant model of cortical dysplasia associated with spontaneous seizures. J Neurosci 21:983-998. 
Winkle CC, McClain LM, Valtschanoff JG, Park CS, Maglione C, Gupton SL (2014) A novel netrin-1-sensitive mechanism promotes local SNAREmediated exocytosis during axon branching. J Cell Biol 205:217-232. CrossRef Medline

Winkle CC and Gupton SL (2016) The Ins and Outs of Neural Connectivity Membrane Trafficking in Neuronal Development. International Review of Cell and Molecular Biology. Elsevier Academic Press. Vol. 322. Chapter 4:247-280.

Witter MP (2007) Intrinsic and extrinsic wiring of CA3: indications for connectional heterogeneity. Learn Mem 14:705-713. CrossRef Medline

Xavier GF, Oliveira-Filho FJ, Santos AM (1999) Dentate gyrus-selective colchicine lesion and disruption of performance in spatial tasks: difficulties in 'place strategy' because of a lack of flexibility in the use of environmental cues? Hippocampus 9:668-681. CrossRef Medline

Yamagishi S, Yamada K, Sawada M, Nakano S, Mori N, Sawamoto K, Sato K
(2015) Netrin-5 is highly expressed in neurogenic regions of the adult brain. Front Cell Neurosci 9:146. CrossRef Medline

Yang F, Wang CJ, Han JL, Zhao G, Jiang W (2008) Different effects of mild and severe seizures on hippocampal neurogenesis in adult rats. Hippocampus 18:460-468. CrossRef Medline

Yang L, Li R, Kaneko T, Takle K, Morikawa RK, Essex L, Wang X, Zhou J, Emoto K, Xiang Y, Ye B (2014) Trim9 regulates activity-dependent fine-scale topography in Drosophila. Curr Biol 24:1024-1030. CrossRef Medline

Yung AR, Nishitani AM, Goodrich LV (2015) Phenotypic analysis of mice completely lacking netrin 1. Development 142:3686-3691.

Zhou M, Li W, Huang S, Song J, Kim JY, Tian X, Kang E, Sano Y, Liu C, Balaji J, Wu S, Zhou Y, Zhou Y, Parivash SN, Ehninger D, He L, Song H, Ming GL, Silva AJ (2013) mTOR inhibition ameliorates cognitive and affective deficits caused by discl knockdown in adult-born dentate granule neurons. Neuron 77:647-654. CrossRef Medline 